\title{
Fruit and vegetable by-products as novel ingredients to improve the nutritional quality of baked goods
}

\author{
Manuel Gómez ${ }^{1}$, Mario M. Martinez ${ }^{2 *}$ \\ ${ }^{1}$ Food Technology Area, College of Agricultural Engineering, University of Valladolid, Palencia, Spain. \\ ${ }^{2}$ Whistler Center for Carbohydrate Research, Department of Food Science, Purdue University, 745 \\ Agriculture Mall Drive, West Lafayette, IN 47907, USA. \\ *Corresponding author e-mail: mariomartinez175@gmail.com; mart1269@purdue.edu
}

\begin{abstract}
The industrial manufacturing of fruits and vegetables generates approximately $50 \%$ byproduct waste, causing a negative environmental impact and significant expenses. Nevertheless, fruit and vegetable by-products (FVB) are rich nutrients and extranutritional compounds that contribute to bowel health, weight management, lower blood cholesterol levels and improved control of glycemic and insulin responses. Due to the positive influence of FVB fibers and bioactive compounds during the digestion of glycemic carbohydrates, such as starch, baked goods are ideal food systems to accommodate FVB, since most of them have a high glycemic index. Therefore, this is an area of recent interest with critical environmental, economic and health implications worldwide. However, the utilization of FVB in baked goods leads to the loss of acceptability, in many cases caused by a lack of understanding of the physical structure and composition of FVB and their effects on food quality. The objective of this review is to provide a mechanistic understanding of the impact of the physical structure and composition of FVB on common baked goods and their influence on the nutritional and physical quality of the resulting product. This review will support the use of FVB as ideal ingredients while improving the added value of waste streams.
\end{abstract}

Keywords: cellulose, pectin, fiber, by-product, polyphenols, bread 


\section{Introduction}

The industrial manufacturing of fruits and vegetables generates approximately $50 \%$ byproduct waste in the form of peels, cores, pomace, unripe and/ or damaged fruits and vegetables (Padayachee et al., 2017). By-product materials are highly prone to enzymatic and microbial deterioration (Russ and Meyer-Pittroff, 2004) and their disposal entails an elevated environmental impact and significant expenses. Fruit and vegetable by-products (FVB) are usually reutilized for animal feed or processed into biogas or compost to obtain biofertilizer. Nevertheless, FVB are rich in nutrients and extranutritional compounds that contribute to bowel health, weight management, lowering of blood cholesterol and improving control of glycemic and insulin responses. As an example, FVB contain soluble fibers that can impact passage rate, viscosity, and interactions with digestive enzymes and bile salts in the stomach and small intestine (Gunness et al., 2016a,b; Padayachee et al., 2017). These phenomena are expected to slow down many of the processes associated with the digestion of glycemic carbohydrates (Dhital et al., 2017). Due to the positive influence of FVB constituents during the digestion of glycemic carbohydrates, such as starch, baked goods can be considered model food systems to accommodate FVB, since most of them are categorized as having high a glycemic index (Foster-Powell et al., 2002). In fact, a literature database search on the topics "by-product and bread" as well as "by-product and biscuit or cookie or muffin" in Web of Science in January 2017 yielded 242 articles. Fig. 1a shows the time distribution of the 242 articles concerning the use of byproducts in breads (157 articles) and muffins, biscuits or cookies (85 articles). Since 2013, more than 30 research articles have been published every year. Moreover, the number of citations has exponentially grown since 2010 (Fig. 1b), reaching more than 450 citations in 2016. Thus, in recent years, effective management of the large amounts of by-product waste output from fruit and vegetable processing has become an area of major environmental and economic importance world-wide.

The objective of this review is to provide a comprehensive understanding of the effect of the physical properties and origin of FVB on the nutritional and physical quality of commonly consumed baked goods (breads, cakes and cookies). To do so, this review starts with a brief insight of the advantages and challenges of the incorporation of FVB in baked goods. Then, the most outstanding FVB, both for their global availability or their suitability as a feedstock of bioactive compounds, are mentioned in brief. To 
conclude, a systematic overview about the fortification of baked goods with FVB is covered more in detail.

\section{Brief insight of the positive and negative aspects of FVB incorporation into baked goods}

\subsection{Advantages}

The health functionality of plant cell wall components from fruits and vegetables has been recently reported in depth by Padayachee et al., (2017) with a particular emphasis on interactions between cell walls and phytonutrients. These interactions, together with the potential disruption of the plant cell tissue during processing and the ultimate physical treatments for FVB preparation, are the basis for the compositional, structural and physical properties of FVB as ingredients. FVB are mainly composed of water and organic constituents (Russ and Meyer-Pittroff, 2004). The composition of the organic dry matter depends on the origin (type of fruit/vegetable), degree of ripening of the raw fruit/vegetable and the manufacturing process (e.g. cans, jam, juice, etc.).

\subsubsection{Dietetic fiber}

FVB are characterized by high fiber content, e.g. up to $93.2 \mathrm{~g}$ of fiber per $100 \mathrm{~g}$ of solids in apple pomace (Nawirska and Kwasniewska, 2005). In particular, FVB may be an important source of pectin (in the case of fruits), cellulose (from peels), hemicellulose (from pomace) and lignin (from peels and seed coats) (Banerjee et al., 2017). Dietary fiber can affect the health of gut microbial populations during fiber fermentation. Degradation of carbohydrates in the large bowel yields mainly short-chain fatty acids (SCFAs) (acetate, propionate, and butyrate), which have beneficial effects on the intestinal epithelium and gut immune system (Verspreet et al., 2016). However, the physiological effect of FVB fibers depends on their physicochemical properties, and their solubility is demonstrated to play a crucial role. Highly stable crystalline fibers with tightly arranged molecules are typically insoluble (e.g. cellulose), whereas isolated fibers with more irregularities in their configuration tend to be soluble, such as pectins (Verspreet et al., 2016). Insoluble fibers are essentially insoluble in water and gastrointestinal fluids, and they are typically present as relatively dense particles which resist penetration by colonic microbiota and therefore show a strong resistance to fermentation by gut bacteria, enabling dietary fiber to play a major role in bowel scouring, promotion of healthy colonic epithelia, and bulky stool development (Padayachee et al., 2017). Soluble fibers, on the other hand, can be swollen or dissolved 
in water to form viscous solutions or gels. Compared to insoluble fibers, soluble fibers are more readily fermented by the microflora of the large intestine (Brownlee, 2011). Unlike insoluble fibers, soluble fibers can impact passage rate, viscosity, and interactions with digestive enzymes and bile salts in the stomach and small intestine (Gunness et al., 2016a,b; Padayachee et al., 2017). As mentioned before, these phenomena are expected to slow down many of the processes associated with the digestion of starch and other glycemic carbohydrates, such as gastric emptying, small intestinal transit, mixing of enzymes with substrates, and transport from the lumen to mucosal surface (Dhital et al., 2017). In fact, several studies have shown that the addition of soluble fibers in ingested food significantly reduces the postprandial rise in levels of blood glucose, insulin, and cholesterol in human subjects (Jenkins et al., 1978; Ellis et al., 1981; Gunness et al., 2016a). This may result in special interest in starchy foods, such as baked goods, as many are characterized by a high starch bioaccessibility and therefore a high glycemic response.

\subsubsection{Phenolic compounds}

FVB are also characterized by a high content of polyphenols depending on their origin (e.g. $274 \mathrm{mg} / 100 \mathrm{~g}$ in sweet cherry). In fact, many of the fruit and vegetable precursors for such by-products are classified among the 100 richest dietary sources of polyphenols (Perez-Jimenez et al., 2010). The redox properties of some polyphenols may explain the considerable interest in their role in the prevention of several major chronic diseases associated with oxidative stress, such as cardiovascular diseases, cancers, type 2 diabetes, neurodegenerative diseases or osteoporosis (Martínez-Valverde et al., 2000; Scalbert et al., 2005). Some phenolics are also known for their potential inhibitory effects on obesity and their underlying molecular signaling mechanisms (Hsu and Yen, 2008). FVB may also contain a lipophilic bioactive group of extranutritional compounds termed carotenoids. Orange carrots, orange sweet potato, nectarines and mangoes are the most well-known dietary sources of $\beta$-carotene; lutein can be sourced from green leafy vegetables; zeaxanthin is found in "yellow" foods such as yellow squash, sweet corn and yellow carrots; watermelon, tomatoes, pink grapefruit and red papaya are some of the greatest dietary sources of lycopene (Padayachee et al., 2017). In line with the antioxidant behavior displayed by many bioactive compounds, carotenoids are able to suppress free radical damage. Some carotenoids have been reported to reduce the risk of certain cancers, potentiate the functions of the immune 
system, protect against cataract formation, coronary heart diseases and stroke, and, in the case of beta-carotenes, prevent vitamin A deficiency (Maiani et al., 2009).

\subsection{Challenges}

Despite the environmental and nutritional advantages, the utilization of FVB in cerealbased foods results in a loss of quality, which is why they must be added in small quantities. In all cases, plant-by products lead to baked goods with extraneous flavor and different color (see section 5). Added to that, they interfere with dough structure affecting its expansion which negatively impacts the sensory quality of the resulting food (see section 5). Therefore, the interplay between FVB and the other the dough components depends on many intrinsic factors, including composition (which mainly depends on the plant origin, e.g. citrus fruits, carrot, banana) and physical properties (e.g. particle size, water binding capacity, gel-formation activity). Furthermore, other extrinsic factors, such as the type of baked good (e.g. bread, cake, cookie) and manufacturing conditions, should be taken into consideration.

\section{Most commonly used fruit and vegetable by-products}

Several reviews about the composition and physical properties of FVB have been published from a nutritional standpoint (Schieber et al., 2001; Balasundram et al., 2006; Elleuch et al., 2011; O’Shea et al., 2012; Babbar et al., 2015). Additionally, specific reviews have been published that focus on a single by-product category, most notably: banana (Padam et al., 2014), apple (Shalini and Gupta, 2010; Rabetafika et al., 2014), grape (Fontana et al., 2013; Yu and Ahmedna, 2013), mango (Jahurul et al., 2015; Delgado and Fleuri, 2016; Torres-León et al., 2016), citrus fruits (Ledesma-Escobar and Luque de Castro, 2014; Delgado and Fleuri, 2016), berry (Struck et al., 2016), byproducts from wine making (Arvanitoyannis et al., 2006; Garcia-Lomillo and GonzalezSanJosé, 2017) and fiber from fruit pomaces (Quiles et al., 2017). However, the differences found in the composition and physical properties of FVB, even among FVB from the same plant tissue, affect food quality differently and therefore make it difficult for bakers/manufacturers to find the optimum FVB and level.

\subsection{Apple and grape by-products}

Apple and grape by-products are the FVB on which the highest number of scientific papers have been published. It may be expected since apples and grapes are the two most processed fruits worldwide, especially for juice and beverage-making. In both cases, the seeds are usually removed to avoid contamination with toxic agents 
(Bolarinwa et al., 2015) and the so-called caking effect (due to the oil fraction); this removal typically prevents the production of FVB-based fine flours (García-Lomillo et al., 2014). Apple and grape by-products are known to have a high fiber content, comprised mainly of insoluble fibers (cellulose and hemicellulose), although they also contain a substantial amount of pectin $(\geq 10 \%)$, especially when they come from apple pomace. Both of them contain a significant amount of phenolics. Apple pomace and peels contain magnesium, calcium, quercetin and procyanidin (flavonoids) and phenolic acids whereas grape pomace is a notable source anthocyanins and flavonols (flavonoids) as well gallic acid (phenolic acid). Polyphenols from grape have been reported to modify intestinal glucose transport in a coupled in vitro digestion/caco-2 human intestinal model (Moser et al., 2016) and therefore they may potentially decrease the glycemic response of the rest of glycemic carbohydrates present in a meal. The composition and functional properties of such FVB depend on their origin, ripening degree, previous thermal and enzymatic (pectinases) treatments in the case of apple (Aguedo et al., 2012; Rabetafika et al., 2014), and even on the type of manufacturing process from which by-products are obtained, such as must or wine, in the case of grapes (Kammerer et al., 2004; Gonzalez-Centeno et al., 2010; Deng et al., 2011; Fontana et al., 2013). In the case of grape by-products, antimicrobial (Garcia-Lomillo et al., 2014) and probiotic (Gil-Sanchez et al., 2017) properties have been also found.

\subsection{Tropical fruits by-products (banana and mango)}

Banana and mango are the most predominant tropical fruits. Banana flour, which is the main by-product obtained from the pulp of green bananas, is obtained after drying and milling the pulp from defect-containing fruits. Conversely to other fruits and vegetables, banana contains an important amount of starch (up to 80\%) that is transformed to sugars during its ripening stages (Zhang et al., 2005). Native banana starch presents higher resistance to digestive enzymes (Englyst and Cummings, 1986) compared to that from other cereals and tubers (Faisanta et al., 1995; Zhang and Hamaker, 2012), even after cooking (Zhang and Hamaker, 2012), which has the potential to be used for making low

glycemic foods. Banana flour contains an important fraction of dietary fiber [up to $15 \%$ in some varieties, (da Mota, et al., 2000)], consisting mainly of pectin (soluble fraction) and cellulose, lignin and hemicellulose (insoluble fraction). Added to that, banana flour is also characterized by its content in phenolics and antioxidant capacity. Banana peels can also be exploited, but they are a domestic rather than an industrial waste. Therefore, processing large amounts becomes more challenging. In addition, their greater hardness 
and bitter taste impede their utilization, although they have high contents of fiber and phenolic compounds as well as a high antioxidant activity (Arun et al., 2015b). Meanwhile, by-products from mango are derived from its peel and pulp, and they contain a high level of fiber, mainly insoluble fiber (Ajila and Rao, 2013), and bioactive compounds (Ajila et al., 2010), such as carotene and flavonoids. The composition of mango by-products also depends on the variety, ripening degree and previous treatments, such as blanching, drying or irradiation (Ajila et al., 2007; Dorta et al., 2012, 2014; Geerkens et al., 2015). The inhibition capacity of mango phenolics towards digestive enzymes ( $\alpha$-amylases and mucosal $\alpha$-glucosidases) has been also reported (Gondi and Rao, 2015). Thus, mango by-products may be beneficial for reducing the digestion rate of glycemic carbohydrates present in baked goods, and therefore the glycemic response.

\subsection{Citrus fruit by-products}

Citrus fruits are also widely consumed and processed. Essential oils and pectin can be industrially obtained from citrus peels (main by-product). For this reason, and for their high astringency, the use of citrus peels as by-products in foods is less common. The majority of the studies about citrus fruits are focused on the use of their fibers, which can be obtained during the recovery of essential oils. The fibers present in citrus peels are mainly insoluble, with a soluble to insoluble fiber ratio of 1:5 (Chau and Huang, 2003; Figuerola et al., 2005), and with appreciable amounts of pectin.

\subsection{Berry by-products}

By-products from berries are featured for their high content in phenolics, especially anthocyanins (flavonoids), with high antioxidant capacity. However, the main component from berry pomace is the fiber ( $\sim 70 \%$ mainly insoluble) followed by protein (15\%) (Sojka et al., 2013a,b). This composition depends on the type of berry (Struck et al., 2016) and drying treatments (Horszwald et al., 2013). Like mango peel, berry pomace has been reported to reduce the glycemic response by the inhibitory effect of polyphenols on the catalytic activity of digestive amylase and $\alpha$-glucosidases (Flores et al., 2013).

\subsection{Vegetable by-products}

Among by-products from processing vegetables, those from tomato are notable for their high lycopene content (Knoblich et al., 2005). This compound is gaining prominence for its antioxidant and carcinoprotective properties (Friedman, 2013) and its capacity to prevent cardiovascular diseases (Muller et al., 2016). Moreover, tomato pomace is rich 
in fiber, mainly insoluble, and contains a significant amount of sugars [especially glucose and fructose (Davies and Kempton, 1975)] and protein (Del Valle et al., 2006). In the case of carrot pomace, like in other by-products, the fiber fraction is the most abundant, with a soluble to insoluble fiber ratio of 1:4. Carrot pomace is especially relevant for its content of carotenoids, mainly beta-carotene (Surles et al., 2004) followed by phenolics (Sun et al., 2009). However, carrot is susceptible to loss of its bioactive phytochemicals when it is dehydrated at high temperatures $\left(<65^{\circ} \mathrm{C}\right)$ or stored at temperatures higher than $45^{\circ} \mathrm{C}$ (Chen and Tang, 1998; Upadhyay et al., 2008).

To conclude, by-products obtained from potato peel are especially relevant because large amounts are industrially generated. Like other by-products, potato peel is rich in fiber, although it depends on the peeling procedure and the possible contamination with starch (Camire et al., 1997). Potato peel also contains a high content of phenolic compounds (Im et al., 2008; Mattila and Hellström, 2007) with a high antioxidant and antidiabetic capacity, the latter being higher in young potatoes (Arun et al., 2015a).

Apart from the aforementioned by-products, which are the most predominant, studies about the utilization of other less common by-products will be also covered in the following section.

\section{Utilization of FVB in common baked goods}

Since most of the baking processes are optimized for each baked product (formulation, water, mixing fermentation, baking conditions, etc.), food scientists and technologists have mainly attempted to optimize the utilization of FVB by: 1) controlling the amount used and 2) selecting the best source of FVB. However, less effort has been made on obtaining systematic information on the physical properties of FVB and their effects on food quality.

In the majority of cases, the inclusion of FVB has led to a decline in food acceptability. In a review of the acceptability of cereal-based products enriched with fibers, Grigor et al. (2016) claimed that if the original food has good acceptability, a fiber enrichment usually declines its quality, especially if extensive. Thus, the inclusion of FVB, which contains a large fraction of fiber (up to 93.2\%), in baked goods may have similar effects on reducing the food quality as purified fibers. Meanwhile, many phenolic compounds are bitter, acrid, or astringent and therefore objectionable to the consumer (Drewnowski and Gomez-Carneros, 2000). In any case, the effect of the incorporation of FVB on the 
food product depends on the type of baking food system, which will be individually reviewed in the following sections.

\subsection{Bread}

Studies on the addition of FVB in wheat breads involved the use of grape pomace (Hayta et al., 2014), grape wine pomace (Mildner-Szkudlarz and Bajerska, 2013; Walker et al., 2014), pear, apple and date pomace (Bchir et al., 2014), banana pseudostem flour (Ho et al., 2013, 2015), green banana flour (Juarez-Garcia et al. 2006; Mohamed et al., 2010), pomegranate peel (Altunkaya et al., 2013), pomegranate bagasse (Bohl et al., 2016), citrus peel (Shyu et al., 2014), tomato waste (Nour et al., 2015), potato peel (Orr et al., 1982) onion skins (Gawlik-Dziki et al., 2013, 2015; Swieca et al., 2013) and lesser known fruit residues, such as cupuassu peel (Salgado et al., 2011). In some cases, due to the poor organoleptic characteristics of FVB, the incorporation of fibers extracted from them is preferred, e.g. fibers extracted from citrus fruits (Miller, 2011; Stoll et al., 2015), potato peel (Curti et al., 2016) and pineapple pomace (Chareonthaikij et al., 2016). There are also studies on the incorporation of other by-products, or their fibers, in special breads. Thus, tomato pomace (Majzoobi et al., 2011); apple pomace, papaya peels and watermelon rinds (Waghmare and Arya, 2014); and banana peel powder (Kurhade et al., 2016) have been studied in flat breads. Fibers from pineapple peel (Wu and Shiau, 2015) and lemon pomace (Fu et al., 2015) have been studied in steamed breads, and the addition of ripe mango peel (Pathak et al., 2016), grape by-products (Mildner-Szkudlarz et al., 2011) and apple pomace (Sudha et al., 2016) have been reported in whole breads, rye breads and buns, respectively. In Table 1, a partial listing of papers is shown summarizing the practical uses of FVB in breads.

\subsubsection{Physical and sensory quality of bread as affected by FVB}

In the aforementioned studies, the replacement of wheat flour by the by-product never exceeded 10\%, except for the study by Kurhade et al. (2016) using chapatti, which had levels that reached $20 \%$. In general, a loss in bread acceptability was already observed with low FVB addition. This loss in bread quality consisted mainly of a reduction in bread volume and sensory acceptability and an increase in crumb hardness. The increase of the viscoelastic moduli, G' and G'' (Ktenioudaki et al., 2013; Pathak et al., 2016) and resistance to extension, i.e. decreased extensibility (Ktenioudaki et al., 2013; Bchir et al., 2014; Fu et al., 2015; Wu and Shiau, 2015), of doughs containing FVB confirm the need for adding more water to the formulation and, in some cases, the need for 
extending the kneading time (Bchir et al., 2014; Shyu et al., 2014; Chareonthaikij et al., 2016). The same authors also observed that doughs containing FVB possessed lower kneading stability, except for Bchir et al. (2014), who found unusually low optimum kneading parameters. Results from the latter may be due to the fact that doughs with a high content of fiber display an initial peak in the farninograph as a consequence of the rapid water absorption by the fiber (Stauffer, 1990). Then, the dough relaxes and the elastic gluten network develops as kneading progresses, resulting in a second peak, which is the one that should be considered. The implications of FBV addition in dough rheology and mixing properties resemble those of the incorporation of fiber (Gomez et al., 2003; Rosell et al., 2006), supporting the hypothesis that the fiber fraction of FVB may account for these differences. Many fibers present in fruit and vegetables are hydrophilic and have a natural affinity for water, which makes them ideal candidates to increase the viscosity of bread systems. The lower volume and higher hardness of breads containing FVB is also attributed to the reduction of gluten in the dough due to the partial substitution of wheat flour by FVB. As the gluten network is mainly responsible for holding gas during fermentation, reduced gluten could viably result in breads with lower volume. Different studies about fiber addition in breads have reported similar effects (Gomez et al., 2003; Rosell and Santos, 2010). On the other hand, the incorporation of small quantities of fibers with high water retention capacity (termed gums or hydrocolloids) was reported to be beneficial for the physical quality of breads (Rosell et al., 2001; Guarda et al., 2004). Thereby, FVB with higher pectin content, such as those from apple, may minimize the negative effects, such as low volume and high hardness. Changes in crumb color were also detected. During baking, Maillard reactions are not produced in the crumb since it does not reach $100^{\circ} \mathrm{C}$. Therefore, crumb color is highly affected by the color of its components. In the case of flat bread, a reduction of its extensibility was also reported (Waghmare and Arya, 2014; Kurhade et al., 2016).

Special attention is required for banana by-products due to their high starch content. For this reason, addition levels of $30 \%$ can be attained without reducing bread volume (Mohamed et al., 2010). In fact, Juarez-García et al. (2006) fully replaced wheat flour by banana flour in bread-making, although these authors did not measure any quality parameters of the resultant breads. In both studies, vital gluten was added (20-25\%) in order to compensate for the gluten dilution. Doughs containing banana flour have higher water absorption capacity and lower kneading tolerance. On the other hand, banana breads have similar volume and lower hardness than wheat breads (Mohamed et al., 
2010). These changes may be attributed to the composition of banana flour, and in particular to its damaged starch and fiber fractions, which possess the capacity to absorb and retain water and thus improve the texture (lower hardness). However, the similar quality of banana and wheat breads in these studies may be attributed to the incorporation of vital gluten in the recipes with banana, since it increases water absorption of the dough and is known to increase bread volume and decrease hardness. The negative effects of FVB on bread acceptability are generally related to lower volume and different color, observed by consumers as increased hardness and unfavorable external appearance, respectively. Moreover, phenolics and other bioactive compounds in fruit and vegetables are generally quite unpalatable, tasting bitter, acrid or astringent, as they biologically serve as protection for the fruit and vegetable against premature consumption by herbivore predators (Padayachee et al. 2017). Therefore, the acerbic taste can negatively influence bread flavor and acceptability. On the other hand, surprisingly, the incorporation of FVB does not always result in a lower acceptability (Gawlik-Dziki et al., 2013; Waghmare and Arya, 2014); however, in some cases, this outcome was achieved by either the use of a complex recipe (with strong and seasoned flavors) or by making flat breads, in which volume and hardness are not crucial factors (Waghmare and Arya, 2014). It must be noted that the vast majority of studies contained sensory analyses with scarce numbers of panelists (sometimes lower than 15 and rarely higher than 30). Acceptability studies should be performed with a substantial number of panelists, who have not received previous training and who are unrelated to the investigation (Hough et al., 2006). These requirements were not met in the majority of the studies. This is an important consideration since acceptability studies are a main aspect in industrial applications.

The use of FVB has also been found to reduce bread staling (Curti et al., 2016), which is a desirable impact on bread quality. This effect could be related to the fiber content present in FVB, as already reported with the use of purified fibers (Gomez et al., 2003). Fiber may reduce the retrogradation kinetics of amylopectin molecules (Santos et al., 2008; Ronda et al., 2014) and increase the water retention capacity of the final bread (Almeida et al., 2013). This effect depends on the amount of fiber and its origin. Thus, FVB with higher pectin content, especially by-products from citrus fruits and apple, can significantly increase the water absorption of the dough during mixing and the water retention of bread during storage (Rosell et al., 2001; Guarda et al., 2004; Almeida et al., 2013). 


\subsubsection{Nutritional improvement of bread through the utilization of FVB}

In all cases, the use of FVB in breads has resulted in nutritional improvement, consisting mainly of enrichment in fiber (Salgado et al., 2011; Ho et al., 2013; MildnerSzkudlarz and Bajerska, 2013; Walker at al., 2014; O'Shea et al 2015) and phenolics (Ho et al., 2013; Mildner-Szkudlarz and Bajerska, 2013; Hayta et al., 2014; Fu et al., 2015; Gawlik-Dziki et al., 2015; Bhol et al., 2016; Kurhade et al., 2016; Pathak et al., 2016; Sudha et al., 2016). The health benefits of foods rich in fiber was already discussed in section 1 . However, it is noteworthy that in vivo, the physical properties of FVB fiber networks may be influenced by other factors in the human gastrointestinal system, including $\mathrm{pH}$, ionic environment and the presence of bile acids, as well as the presence of other dietary components (Padayachee et al. 2017). Nevertheless, there is direct evidence that consumption of dietary fiber affects the viscosity of human gastric and small intestinal digesta (Dikeman and Fahey, 2006). Despite the fact that thermal treatments during baking may alter phenolics, results from different studies have indicated that a significant amount of polyphenols still remain in bread after processing. Therefore, it is not surprising to find studies reporting a nutritional improvement (in vivo) after the consumption of breads containing such FVB. As an example, the use of dried powdered grape skins diminished the negative impact of a high-cholesterol/cholic acid diet by lowering total cholesterol (TC), low-density lipoprotein cholesterol (LDLC) and lipid peroxidation of breads (Mildner-Szkudlarz and Bajerska, 2013). In another study, Sudha et al. (2016) observed improved free radical scavenging as well as cyto/DNA protective properties for buns enriched with apple pomace. Breads contain an important amount of starch, a glycemic carbohydrate which undergoes gelatinization during baking as a consequence of the elevated temperatures in an excess of water. The amorphous structure of gelatinized starch results in greater availability of $\alpha$-amylase binding sites, which makes the starch (substrate) more susceptible to enzyme hydrolysis (Baldwin et al., 2015) and results in breads with high glycemic index (Foster-Powell et al., 2002). Since many FVB are rich in soluble fibers and polyphenols, the glycemic response for breads containing FVB may be expected to improve (the mechanistic effects of soluble fibers and polyphenols on the glycemic response of foods was briefly described in section 1). In particular, Coe and Ryan (2016) reported epidemiological data indicating that polyphenols reduce the peak and early-phase glycemic response and maintain the glycemic response in the later stages of digestion, suggesting that polyphenols in foods may have a beneficial effect on reducing the risk for type 2 
diabetes. However, this effect has not been studied in depth in breads enriched with the most common FVB. Waghmare and Arya (2014) observed a reduction of the in vitro glycemic response [hydrolysis index, HI (Goni et al., 1997)] of flat breads that was dependent on the type of FVB added. In the same way, Borczak et al., (2016) demonstrated that the addition of certain freeze-dried fruits with an elevated content of polyphenols, such as elderberry, can increase the amounts slowly digestible starch (SDS) and resistant starch (RS) of whole breads. Therefore, adding FVB to breads could reduce the glycemic response, potentially making it a useful tool to prevent hyperglycemia-related diseases.

\subsubsection{Effects of the physical properties and composition of FVB on bread quality}

The majority of studies have been limited to incorporating certain FVB in product formulations without prior optimization for physical properties, which may not only affect the loss of bread quality but also the physiological effects of fibers and phenolics (Eastwood and Morris, 1992). A limited number of studies have focused on the effect of previous processing of FVB, such as drying or milling, on the quality of breads. Shyu et al. (2014) observed that low drying temperatures $\left(100\right.$ instead $\left.150^{\circ} \mathrm{C}\right)$ improved the acceptability of breads made with citrus peel, although high temperature increased the presence of phenolics and antioxidant properties of citrus peel. The authors mentioned that the higher content of highly astringent polyphenols could have reduced the acceptability of such breads. Meanwhile, Wu et al. (2015) observed that the addition of fibers from pineapple peel with coarser particle size resulted in breads with higher volume and lower hardness than those made with finer fibers. This is in agreement with the results shown by Hemdane et al. (2015) using wheat by-products with different particle sizes. The viscosity and rheological properties exhibited by FVB depend on the physical interaction between FVB particles, which are strongly associated with fiber microstructure (i.e. fiber particle size and deformability). Moreover, fine particles, with higher surface area, may interact to a greater extent with the gluten network, more negatively affecting bread quality than coarse particles. However, most studies have not specified the FVB particle size. Likewise, other ways to minimize the negative effects of the incorporation of FVB should be studied, for example, through the use of additives, such as emulsifiers, oxidants, gums or gluten, or enzymes. These components have successfully minimized the negative effects of the addition of fibers in breads (Gomez and Oliete, 2016). In fact, Sudha et al. (2016) improved the quality of buns with apple pomace through a combination of gluten and emulsifiers; and Ho et al. 
(2013) improved the quality of breads containing banana pseudo-stem flour with the addition of carboxymethyl cellulose (CMC), which was not observed with xanthan gum. Therefore, proper selection of the type and amount of additive is also important.

\subsubsection{FVB in gluten-free breads}

In the case of gluten-free breads, studies are scarce and only the addition of orange pomace (O'Shea et al., 2013, 2015) and tiger-nut by-product (Aguilar et al., 2015) have been investigated. These breads are, in fact, a good opportunity for the incorporation of FVB with good nutritional properties, since they possess lower fiber content and poorer nutritional quality than wheat breads (Capriles and Areas, 2014; Matos and Rosell, 2015). Gluten-free bread-making is challenging, especially considering the difficulty in making the dough expand in the absence of gluten. Capriles and Areas, (2014) and Matos and Rosell, (2015) showed an increase in the storage modulus (G') of the dough with the use of fibers, which may be explained by their high water absorption capacity. Added to that, the resulting breads had a lower volume and an increased hardness. In this case, the results cannot be attributed to the dilution of the gluten network or its interactions. Nonetheless, it is known that higher values of $G^{\prime}$ (doughs highly consistent) are related to a lower expansion during fermentation and, therefore, result in breads with lower volume (Mancebo et al., 2015b). This effect can be minimized by increasing the water content in the formulation as well as by increasing the fermentation time (O'Shea et al., 2015). The incorporation of green banana flour has also been studied, showing breads containing $30 \%$ of banana flour in a complex combination of gluten-free flours maintained appropriate acceptability, although the water content needed to be increased (Sarawong et al., 2014) in order to reduce the dough consistency and allow its expansion. In fact, Seguchi et al. (2014), by combining banana and wheat starches, found that overripe banana possesses better properties for bread-making than green or yellow bananas, which the authors attributed to its higher enzymatic content (amylases and proteases). However, the amount of fermentable sugars (simple sugars) of overripe banana flours may likely have a key role in modifying the dough consistency.

\subsection{Cakes}

The incorporation of FVB in cakes can reach higher levels ( $\geq 30 \%$ flour replacement) than breads. This is mainly due to: 1) no requirement for a gluten network; 2) the lower flour fraction in the overall recipe and; 3) the higher amount of other ingredients, such as sugars, that can mask or minimize the bitter taste from FVB. Among cakes, which 
are produced from baking a whisked batter, two main groups are predominant. The first one comprises cakes with low lipid content, where the emulsion is fine (high number of fine bubbles) and where egg white proteins play a key role. Sponge cakes are classified within this group. On the other hand, the second group is composed of cakes with higher lipid content (oil or shortening) resulting in a coarse emulsion (lower number of coarse bubbles) that is stabilized by the presence of lipids and where the gas expansion is attained by the use of baking powder. Muffins and layer cakes are examples of cakes classified within this group.

The majority of studies on the incorporation of FVB into cakes have been done on muffins (similar recipes to layer cakes). These baking products are less sensitive to flour substitution and to particle size of the different ingredients than sponge cakes. In addition, layer cakes possess more lipids that can mask the unfavorable taste from FVB. Thus, mango by-products (Aziah et al., 2011; Ramirez-Maganda et al., 2015; Sudha et al., 2015), grape by-products (Walker at al., 2014; Mildner-Szkudlarz et al., 2015), sour cherry pomace (Bajerska et al., 2016), berry pomace (Mildner-Szkudlarz et al., 2016) apple skins (Rupasinghe et al., 2008, 2009), apple pomace (Sudha et al., 2016), green banana flour (Segundo et al., 2017), orange fibers (Romero-López et al., 2011), date fruit fiber concentrates (Mrabet et al., 2016), carrot pomace (Maazobi et al., 2016), pumpkin seed flour (Bialek et al., 2016), hazelnut skin (Cikrikci et al., 2016) and potato peel (Arora and Camire, 1994; Ben Jeddou et al., 2017) have been studied. In Table 2, a partial listing of papers on practical uses of FVB in cakes is shown.

\subsubsection{Nutritional improvement of cakes through the utilization of FVB}

From a nutritional perspective, all studies have shown an increase in fiber and polyphenols with the addition FVB. Added to that, the in vivo glycemic response was reduced with the incorporation of FVB (Aziah et al., 2011; Romero-López et al., 2011; Ramirez-Maganda et al., 2015; Bajerska et al., 2016). This may be due to the incorporation of soluble fibers with thickening properties, especially in the study of Romero-López et al. (2011), who added orange fiber, which is rich in pectin. The effect of water-soluble fibers on the reduction of the glycemic response of products rich in starch has been demonstrated (Scazzina et al., 2013). In other cases, the presence of phenolic compounds, with potential for the inhibition of digestive enzymes (Coe and Ryan, 2016) or glucose trans-epithelial transporters (Moser et al. 2016), may also be responsible for this nutritional improvement.

\subsubsection{Physical and sensory quality of cakes as affected by FVB}


The incorporation of FVB was associated with decreased muffin/cake volume and height, which also resulted in harder texture (Arora and Camire, 1994; Rupasinghe et al., 2009; Walker at al., 2014; Sudha et al., 2015). With the exception of certain types of pectin, relatively few polysaccharides have sufficient hydrophobic groups to be adequately surface active, and thus the emulsion stabilization will depend on the Pickering effect of the particles that are present in the emulsion. Fine particles, either as starch granules, flour or FVB particles, will tend to adsorb at surfaces to achieve optimum wetting by each phase. Once adsorbed, the energy for detachment is very high and the particle may effectively be permanently attached to the surface (Lam et al., 2014). Thereby, large particles, either flour (Yamazaki and Donelson, 1972) or fibers (Gomez et al., 2010a), have been reported to reduce the volume of cakes, although the negative effect is more evident in sponge than in layer cake (de la Hera et al., 2013; Dhen et al., 2016; Segundo et al., 2017). In general, the typical particle size of wheat flour is $\leq 200 \mu \mathrm{m}$ (usually $\sim 100 \mu \mathrm{m}$ ) whereas the particle sizes of FVB are usually larger, ranging from 400 to $600 \mu \mathrm{m}$ (Romero-López et al., 2011; Walker at al., 2014; Bajerska et al., 2016; Mrabet et al., 2016), and in most cases smaller than $1 \mathrm{~mm}$ (Rupasinghe et al., 2009, Ben Jeddou et al., 2017), depending on their behavior during milling. In particular, FVB with high fiber content are difficult to mill and therefore result in coarse particles, or at least, coarser than $200 \mu \mathrm{m}$. In this way, the lower Pickering effect of large particles may result in increased emulsion air bubble size, which reduces emulsion stability (Gómez et al., 2010b). In fact, Sudha et al. (2015) suggested adding surface active emulsifiers that could stabilize the emulsion in order to attenuate the loss of volume.

As for sensory acceptability, there are contradictory results depending on the type of FVB used. A 30\% addition of grape by-products reduced cake acceptability significantly (Mildner-Szkudlarz et al., 2015), which would explain the lack of significant differences found in formulations containing 10\% of FVB (Walker et al. 2014). Cake acceptability was also reduced with orange fiber (Romero-López et al., 2011). Using mango by-products, cake acceptability was reduced (Sudha et al., 2015) or increased (Ramirez-Maganda et al., 2015) depending on the study, although the sensory test was performed with a limited number of panelists in both cases. Apple skins did not alter cake acceptability (Rupasinghe et al., 2009) whereas potato skins significantly reduced it even at small quantities (Ben Jeddou et al., 2017). These differences may be due to the different FVB colors, which influence the color of cakes, and to the bitter 
taste imparted by phenolic compounds. Differences can also be attributed to the varying amounts of FVB used in the different studies. Nevertheless, like in the case of breads, sensory analyses were performed mostly with an insufficient number of panelists, which should be corrected in future studies.

\subsection{Cookies}

Although there are numerous types of cookies, investigations of the addition of FVB are focused on short cut cookies and cookie dough rich in lipids and sugars. For this reason, like in the case of cakes, cookies better tolerate larger amounts of FVB, since lipids and sugar may mask bitter flavors. Therefore, the majority of the examined studies assessed FVB additions of $\geq 15 \%$ (flour replacement), even reaching $30-35 \%$ in some cases. Studies about the incorporation of fruit by-products in cookies include the addition of apple pomace (Coehlo and Wosiacki, 2010; Kohajdova et al., 2014; Sudha et al., 2016), berry pomace (Saric et al., 2016; Tanska et al., 2016), sour cherry pomace (Saponjac et al., 2016), mango peel (Ajila et al., 2008), banana peel (Arun et al., 2015b), green banana flour (Agama-Acevedo et al., 2012), pumpkin and carrot pomace (Turksoy and Ozkaya, 2011), pomegranate peel (Srivastava et al., 2014), citrus peel powder (Younis et al., 2016), grapefruit and citrus fiber (Kohajdova et al., 2011, 2013), potato peel (Arora and Camire, 1994) and watermelon rind (Naknaen et al., 2016). In Table 2, a partial listing of papers on practical uses of FVB on cookies is shown.

\subsubsection{Nutritional improvement of cookies through the utilization of FVB}

Like in other products, studies focused on nutritional aspects have shown an increase in fiber, especially insoluble, as well as phenolics and antioxidant capacity with the use of FVB. Naknaen et al. (2016) also claimed a reduction of the glycemic index of the resultant cookies made with banana flour, which can be attributed to their higher content of resistant starch.

\subsubsection{Physical and sensory quality of cookies as affected by FVB}

Studies have shown that the incorporation of FVB reduced the expansion of the dough during baking, resulting in cookies with smaller diameter and higher hardness. The expansion of doughs during baking is reduced when flours have high water absorption capacity (Pareyt and Delcour, 2008), which is a physical parameter that is increased in the presence of fiber (Collar et al., 2006) and flour/by-product mixtures (Ajila et al., 2008; Kohajdova et al., 2011, 2013, 2014; Turksoy and Ozkaya, 2011; Srivastava et al., 2014; Naknaen et al., 2016). Although it was not analyzed with the incorporation of FVB, doughs made with mixtures with higher water absorption capacity yielded higher 
consistency (Mancebo et al., 2016), resulting in problems during sheeting. For this reason, increasing the water content in the formulation may be required to compensate for the effects of adding FVB. Meanwhile, the increased hardness of cookies may also be caused by the high level of insoluble fiber present in FVB, as observed in other studies on the incorporation of insoluble fibers (Laguna et al., 2014; Sudha et al., 2007) or ingredients rich in fibers (Gujral et al., 2003).

In general, the inclusion of FVB has led to reduced cookie acceptability. In particular, Younis et al. (2016) observed a lower overall acceptability of cookies made with citrus fibers, which was attributed to the bitter flavors present in the citrus peels. However, these authors reported that the addition of citrus fibers that were previously debitter, by means of soaking in $4 \%$ of sodium chloride or $4 \%$ of sodium bicarbonate overnight, did not result in cookies with lower overall acceptability. Limonin, a triterpene, is responsible for the so-called delayed bitterness of citrus juices (Drewnowski and Gomez-Carneros, 2000). Therefore, it seems that pretreating citrus peels with sodium chloride or sodium bicarbonate may have partially removed limonin, although its amount was not analyzed (Younis et al. 2016). The lower acceptability of cookies containing FVB may also be related to changes in their color (detected in the majority of the studies), which may be due to the different color of the FVB used. Moreover, the higher hardness of cookies also influences their acceptability. The level of FVB addition varies in different studies, depending on the type of FVB and the formulation. Nevertheless, like in breads and cakes, most of the studies have reported sensory analyses with a limited number of panelists.

Studies on the incorporation of FVB in cookie-making lacked a mechanistic understanding on the effect of processing parameters, such as drying temperature, on flavor, and color and polyphenol content of cookies. Nor are there works that analyze the effect of the FVB particle size, which may have a great influence on cookie quality (Mancebo et al., 2015a). The incorporation of additives or changes in the formulation have also not been studied.

\section{Concluding remarks}

The incorporation of FVB in baked goods results in increased amount of insoluble and soluble dietary fiber. Since baked goods have high starch bioaccessibility, and therefore high glycemic index, the role of soluble fibers, such as pectin, on impacting passage rate, rheology and interactions with digestive enzymes in the stomach and small 
intestine may exert a substantial impact in slowing down the digestion of starch and other glycemic carbohydrates present in cereal-based foods. This effect is accompanied by an increase in the content of bioactive compounds, such as polyphenols and carotenoids, some of which are well known for their antioxidant properties and some also for their effect on inhibiting digestive enzymes and reducing intestinal transepithelial transport of glucose, potentially improving glycemic response.

The utilization of FVB, in most cases, results in a loss in food acceptability, attributed mainly to changes in flavor and appearance. Thus, food manufacturers should make a strategic effort to select FVB with optimal composition and physical properties that attenuate the negative effects (maximizing the nutritional benefits) of their incorporation. This includes parameters such as processing conditions and FVB physical properties, such as particle size, which in turn may affect the loss of bioactive compounds in FVB and therefore in the resultant baked food. Secondly, the combination of FVB with certain additives, such as oxidants, emulsifiers or hydrocolloids, should be also considered to minimize the loss of acceptability of baked products containing such by-products.

Extrinsic features more related to the processing variables of the baked good (instead of the by-product itself), including time and temperatures during baking and fermentation, and formulations should also be considered key elements to minimize the loss of acceptability. In particular, masking of their typical bitter flavors (especially in simple formulations, such as breads) through changes in the formulation or processing variables may entail important benefits that lead to a feasible FVB utilization.

To conclude, the positive results from the nutritional standpoint were mainly evidenced as an increase of fiber and bioactive compounds and a decrease in the hydrolysis index. However, it is noteworthy that these findings should also be evidenced in vivo to confirm the physiological benefits on human health imparted by consumption of baked goods containing plant by-products.

\section{Acknowledgements}

Manuel Gomez would like to acknowledge the financial support of the Spanish Ministry of Economy and Competitiveness (Project AGL2014-52928-C2) and the European Regional Development Fund (FEDER). 


\section{References}

Agama-Acevedo, E., Islas-Hernández, J. J., Pacheco-Vargas, G., Osorio-Díaz, P. and Bello-Pérez, L. A. (2012). Starch digestibility and glycemic index of cookies partially substituted with unripe banana flour. LWT - Food Sci. Technol. 46:177-182.

Aguedo, M., Kohnen, S., Rabetafika, N., Vanden Bossche, S., Sterckx, J., Blecker, C., Beauveb, C. and Paquota, M. (2012). Composition of by-products from cooked fruit processing and potential use in food products. J. Food Comp. Anal. 27:61-69.

Aguilar, N., Albanell, E., Minarro, B., Guamis, B. and Capellas, M. (2015). Effect of tiger nut-derived products in gluten-free batter and bread. Food Sci. Technol. Int. 21:323-331.

Ajila, C. M. and Rao, U. J. S. P. (2013). Mango peel dietary fibre: Composition and associated bound phenolics. J. Funct. Foods 5:444-450.

Ajila, C. M., Rao, L. J. and Rao, U. J. S. P. (2010). Characterization of bioactive compounds from raw and ripe Mangifera indica L. peel extracts. Food Chem. Toxicol. 48:3406-3411.

Ajila, C. M., Naidu, K. A., Bhat, S. G. and Prasada Rao, U. J. S. (2007). Bioactive compounds and antioxidant potential of mango peel extract. Food Chem. 105:982-988.

Ajila, C. M., Leelavathi, K. and Rao, U. J. S. P. (2008). Improvement of dietary fiber content and antioxidant properties in soft dough biscuits with the incorporation of mango peel powder. J. Cereal Sci. 48:319-326.

Almeida, E. L., Chang, Y. K. and Steel, C. J. (2013). Dietary fibre sources in bread: Influence on technological quality. LWT-Food Sci. Technol. 50:545-553.

Altunkaya, A., Hedegaard, R. V., Brimer, L., Gokmen, V. and Skibsted, L. H. (2013). Antioxidant capacity versus chemical safety of wheat bread enriched with pomegranate peel powder. Food Funct. 4:722-727.

Arora, A. and Camire, M. E. (1994). Performance of potato peels in muffins and cookies. Food Res. Int. 27:15-22.

Arun, K. B., Chandran, J., Dhanya, R., Krishna, P., Jayamurthy, P. and Nisha, P. (2015a). A comparative evaluation of antioxidant and antidiabetic potential of peel from young and matured potato. Food Biosci. 9:36-46.

Arun, K. B., Persia, F., Aswathy, P. S., Chandran, J., Sajeev, M. S., Jayamurthy, P. and Nisha, P. (2015b). Plantain peel - a potential source of antioxidant dietary fibre for developing functional cookies. J. Food Sci. Technol. 52:6355-6364. 
Arvanitoyannis, I. S., Ladas, D. and Mavromatis, A. (2006). Potential uses and applications of treated wine waste: a review. Int. J. Food Sci. Technol. 41:475-487.

Aziah, A. A. N., Min, W. L. and Bhat, R. (2011). Nutritional and sensory quality evaluation of sponge cake prepared by incorporation of high dietary fiber containing mango (Mangifera indica var. Chokanan) pulp and peel flours. Int. J. Food Sci. Nutr. 62:559-567.

Babbar, N., Oberoi, H. S. and Sandhu, S. K. (2015). Therapeutic and nutraceutical potential of bioactive compounds extracted from fruit residues. Crit. Rev. Food Sci. Nutr. 55:319-337.

Bajerska, J., Mildner-Szkudlarz, S., Gornas, P., and Seglina, D. (2016). The effects of muffins enriched with sour cherry pomace on acceptability, glycemic response, satiety and energy intake: a randomized crossover trial. J. Sci. Food Agr. 96:2486-2493

Balasundram, N., Sundram, K. and Samman, S. (2006). Phenolic compounds in plants and agri-industrial by-products: Antioxidant activity, occurrence, and potential uses. Food Chem. 99:191-203.

Banerjee, J., Singh, R., Vijayaraghavan, R., MacFarlane, D., Patti, A. F. and Arora, A. (2017). Bioactives from fruit processing wastes: Green approaches to valuable chemicals. Food Chem. 225:10-22.

Bchir, B., Rabetafika, H., Paquot, M. and Blecker, C. (2014). Effect of pear, apple and date fibres from cooked fruit by-products on dough performance and bread quality. Food Bioprocess Tech. 7:1114-1127.

Beck, D. E. (2008). Evaluation and management of constipation. Ochsner J. 8(1):25-31. Ben Jeddou, K., Bouaziz, F., Zouari-Ellouzi, S., Chaari, F., Ellouz-Chaabouni, S., Ellouz-Ghorbel, R. and Nouri-Ellouz, O. (2017). Improvement of texture and sensory properties of cakes by addition. Food Chem. 217:668-677.

Bhol, S., Lanka, D. and Don Bosco, S. J. (2016). Quality characteristics and antioxidant properties of breads incorporated with pomegranate whole fruit bagasse. J. Food Sci. Technol. 53:1717-1721.

Białek, M., Rutkowska, J., Adamska, A. and Bajdalow, E. (2016). Partial replacement of wheat flour with pumpkin seed flour in muffins offered to children. CYTA - J. Food 14:391-398.

Bolarinwa, I. F., Orfila, C. and Morgan, M. R. A. (2015). Determination of amygdalin in apple seeds, fresh apples and processed apple juices. Food Chem. 170:437-442. 
Borczak, B., Sikora, E., Sikora, M., Kapusta-Duch, J., Kutyła-Kupidura, E. M. and Fołta, M. (2016). Nutritional properties of wholemeal wheat-flour bread with an addition of selected wild grown fruits. Starch/Stärke 68:675-682.

Brownlee, I. A. (2011). The physiological roles of dietary fibre. Food Hydrocolloids 25(2):238-250.

Camire, M. E., Violette, D., Dougherty, M. P., McLaughlin, M. A. (1997). Potato peel dietary fiber composition: Effects of peeling and extrusion cooking processes. J. Agr. Food Chem. 45:1404-1408.

Capriles, V. D. and Areas, J. A. G. (2014). Novel approaches in gluten-free breadmaking: Interface between food science, nutrition, and health. Comp. Rev. Food Sci Food Saf. 13:871-890.

Chareonthaikij, P., Uan-On, T. and Prinyawiwatkul, W. (2016). Effects of pineapple pomace fibre on physicochemical properties of composite flour and dough, and consumer acceptance of fibre-enriched wheat bread. Int. J. Food Sci. Technol. 51:11201129.

Chau, C. F. and Huang, Y. L. (2003). Comparison of the chemical composition and physicochemical properties of different fibers prepared from the peel of Citrus sinensis L. Cv. Liucheng. J. Agr. Food Chem. 51:2615-2618.

Chen, B. H. and Tang, Y. C. (1998). Processing and stability of carotenoid powder from carrot pulp waste. J. Agric. Food Chem. 46:2312-2318.

Cikrikci, S., Demirkesen, I. and Mert, B. (2016). Production of hazelnut skin fibres and utilisation in a model bakery product. Qual. Assur. Saf. Crops Foods 8:195-206.

Coe, S. and Ryan, L. (2016). Impact of polyphenol-rich sources on acute postprandial glycaemia: a systematic review. J. Nutr. Sci. 5:1-11.

Coelho, L. M. and Wosiacki, G. (2010). Sensory evaluation of bakery products with the addition of apple pomace flour. Cienc. Tecnol. Aliment. 30:582-588.

Collar, C., Santos, E. and Rosell, C. M. (2006). Significance of dietary fiber on the viscometric pattern of pasted and gelled flour-fiber blends. Cereal Chem. 83:370-376.

Curti, E., Carini, E., Diantom, A. and Vittadini, E. (2016). The use of potato fibre to improve bread physico-chemical properties during storage. Food Chem. 195:64-70.

da Mota, R. V., Lajolo, F. M., Ciacco, C., and Cordenunsi, B. R. (2000). Composition and functional properties of banana flour from different varieties. Stärke-Starch 52:6368. 
de la Hera, E., Martínez, M., Oliete, B. and Gomez, M. (2013). Influence of flour particle size on quality of gluten-free rice-cakes. Food Bioprocess Tech. 6:2280-2288.

Drewnowski, A. and Gomez-Carneros, C. (2000). Bitter taste, phytonutrients, and the consumer: a review. Am. J. Clin. Nutr. 72:1424-35.

Del Valle, M., Camara, M. and Torija, M. E. (2006). Chemical characterization of tomato pomace. J. Sci. Food Agr. 86:1232-1236.

Delgado, C. H. O. and Fleuri, L. F. (2016). Orange and mango by-products: Agroindustrial waste as source of bioactive compounds and botanical versus commercial description - A review. Food Rev. Int. 32:1-14.

Deng, Q., Penner, M. H. and Zhao, Y. (2011). Chemical composition of dietary fiber and polyphenols of five different varieties of wine grape pomace skins. Food Res. Int. 44:2711-2719.

Dhen, N., Román, L., Ben Rejeb, I., Martínez, M. M., Garogouri, M. and Gómez, M. (2016). Particle size distribution of soy flour affecting the quality of gluten free cakes. LWT - Food Sci. Technol. 66:179-185.

Dhital, S., Warren, F.J., Butterworth, P.J., Ellis, P.R. and Gidley, M.J. (2017). Mechanisms of starch digestion by $\alpha$-amylase-Structural basis for kinetic properties. Crit. Rev. Food Sci. Nutr. 57, 875-892.

Dikeman, C. L. and Fahey, G. C. (2006). Viscosity as related to dietary fiber: A review. Crit. Rev. Food Sci. Nutr. 46(8):649-663.

Dorta, E., González, M., Lobo, M. G., Sánchez-Moreno, C. and Ancos, B. (2014). Screening of phenolic compounds in by-product extracts from mangoes (Mangifera indica L.) by HPLC-ESI-QTOF-MS and multivariate analysis for use as a food ingredient. Food Res Int. 57:51-60.

Dorta, E., Lobo, M. G. and González, M. (2012). Using drying treatments to stabilize mango peel and seed: Effect on antioxidant activity. LWT - Food Sci. Technol. 45:261268.

Drewnowski, A. and Gomez-Carneros, C. (2000). Bitter taste, phytonutrients, and the consumer: A review. Am. J. Clin. Nutr. 72:1424-1435.

Eastwood, M. A. and Morris, E. R. (1992). Physical-properties of dietary fiber that influence physiological-function - a model for polymers along the gastrointestinal-tract. Am. J. Clin. Nutr. 55(2):436-442.

Elleuch, M., Bedigian, D., Roiseux, O., Besbes, S., Blecker, C. and Attia, H. (2011). Dietary fibre and fibre-rich by-products of food processing: Characterisation, 
technological functionality and commercial applications: A review. Food Chem. 124:411-421.

Ellis, P., Qi, W., Rayment, P., YiLong, R., Ross-Murphy, S., Cho, S. and Dreher, M. (2001). Guar gum: Agricultural and botanical aspects, physicochemical and nutritional properties, and its use in the development of functional foods. In: Handbook of Dietary Fiber, pp. 613-657. Cho, S. S. and Dreher, M. L., Eds., Marcel Dekker, NY (USA).

Englyst, H. N. and Cummings, J. H. (1986). Digestion of the carbohydrates of banana (Musa paradisiaca sapientum) in the human small intestine. Am. J. Clin. Nutr. 44:4250.

Faisant, N., Buleon, A., Colonna, P., Molis, C., Lartigue, S., Galmiche, J. P. and Champ, M. (1995). Digestion of raw banana starch in the small intestine of healthy humans: Structural features of resistant starch. Br. J. Nutr. 73:111-123.

Figuerola, F., Hurtado, M. L., Estévez, A. M., Chiffelle, I. and Asenjo, F. (2005). Fibre concentrates from apple pomace and citrus peel as potential fibre sources for food enrichment. Food Chem. 91:395-401.

Flores, F. P., Singh, R. K., Kerr, W. L., Pegg, R. B. and Kong, F. B. (2013). Antioxidant and enzyme inhibitory activities of blueberry anthocyanins prepared using different solvents. J. Agr. Food Chem. 61:4441-4447.

Fontana, A. R., Antoniolli, A. and Bottini, R. (2013). Grape pomace as a sustainable source of bioactive compounds: Extraction, characterization, and biotechnological applications of phenolics. J. Agric. Food Chem. 61:8987-9003.

Foster-Powell, K., Holt, S. H., and Brand-Miller, J. C. (2002). International table of glycemic index and glycemic load values. Am. J. Clin. Nutr. 76:5-56.

Friedman, M. (2013). Anticarcinogenic, cardioprotective, and other health benefits of tomato compounds lycopene, alpha-tomatine, and tomatidine in pure form and in fresh and processed tomatoes. J. Agric. Food Chem. 61:9534-9550.

Fu, J. T., Chang, Y. H. and Shiau, S. Y. (2015). Rheological, antioxidative and sensory properties of dough and Mantou (steamed bread) enriched with lemon fiber. Lwt-Food Sci. Technol. 61:56-62.

Garcia-Lomillo, J. and Gonzalez-SanJose, M. L. (2017). Applications of wine pomace in the food industry: approaches and functions. Comp. Rev. Food Sci. Technol. 16:3-22. Garcia-Lomillo, J., Gonzalez-SanJose, M. L., Del Pino-Garcia, R., Rivero-Perez, M. D. and Muniz-Rodriguez, P. (2014). Antioxidant and antimicrobial properties of wine 
byproducts and their potential uses in the food industry. J. Agr. Food Chem. 62:1259512602.

Gawlik-Dziki, U., Kaszuba, K., Piwowarczyk, K., Swieca, M., Dziki, D. and Czyz, J. (2015). Onion skin - Raw material for the production of supplement that enhances the health-beneficial properties of wheat bread. Food Res. Int. 73:97-106.

Gawlik-Dziki, U., Swieca, M., Dziki, D., Baraniak, B., Tomilo, J. and Czyz, J. (2013). Quality and antioxidant properties of breads enriched with dry onion (Allium cepa L.) skin. Food Chem. 138:1621-1628.

Geerkens, C. H., Nagel, A., Just, K. M., Miller-Rostek, P., Kammerer, D. R., Schweiggert, R. M. and Carle, R. (2015). Mango pectin quality as influenced by cultivar, ripeness, peel particle size, blanching, drying, and irradiation. Food Hydrocolloids 51:241-251.

Gil-Sanchez, I., Ayuda-Duran, B., Gonzalez-Manzano, S., Santos-Buelga, C., Cueva, C., Martin-Cabrejas, M.A., Sanz-Buenhombre, M., Guadarrama, A., Moreno-Arribas, M.V. and Bartolome, B. (2017). Chemical characterization and in vitro colonic fermentation of grape pomace extracts. J. Sci. Food Agr. DOI: 10.1002/jsfa.8197

Gomez, M., Moraleja, A., Oliete, B., Ruiz, E. and Caballero, P. A. (2010a). Effect of fibre size on the quality of fibre-enriched layer cakes. LWT - Food Sci. Technol. 43:3338.

Gomez, M. and Oliete, B. (2016). Effect of fibre in enriched breads. In: Bread and Its Fortification: Nutrition and Health Benefits, pp. 273-305. Rosell, C. M., Bajerska, J. and El Sheikha A. F., Eds., CRC Press, Boca Ratón, FL (USA).

Gomez, M., Ronda, F., Blanco, C. A., Caballero, P. A. and Apesteguia, A. (2003). Effect of dietary fibre on dough rheology and bread quality. Eur. Food Res. Technol. 216:51-56.

Gomez, M., Ruiz-París, E. and Oliete, B. (2010b). Influence of flour mill streams on cake quality. Int. J. Food Sci. Technol. 45:1794-1800.

Gondi, M. and Rao, U. J. S. P. (2015). Ethanol extract of mango (Mangifera indica L.) peel inhibits alpha-amylase and alpha-glucosidase activities, and ameliorates diabetes related biochemical parameters in streptozotocin (STZ)-induced diabetic rats. J. Food Sci. Technol. 52:7883-7893.

Goni, I., Garcia-Alonso, A. and Saura-Calixto, F. (1997). A starch hydrolysis procedure to estimate glycemic index. Nutr. Res. 17:427-437. 
Gunness, P., Michiels, J., Vanhaecke, L., Smet, S. D., Kravchuk, O., Van de Meene, A., Gidley, M. J. (2016a). Reduction in circulating bile acid and restricted diffusion across the intestinal epithelium are associated with a decrease in blood cholesterol in the presence of oat b-glucan. FASEB J. 30:1-12.

Gunness, P., Williams, B. A., Gerrits, W. J. J., Bird, A. R., Kravchuk, O., Gidley, M. J. (2016b). Circulating triglycerides and bile acids are reduced by a soluble wheat arabinoxylan via modulation of bile concentration and lipid digestion rates in a pig model. Mol. Nutr. Food Res.60:642-651.

González-Centeno, M. R., Rosselló, C., Simal, S., Garau, M. C., Lopez, F. and Femenia, A. (2010). Physico-chemical properties of cell wall materials obtained from ten grape varieties and their byproducts: Grape pomaces and stems. LWT-Food Sci. Technol. 43:1580-1586.

Grigor, J. M., Brennan, C. S., Hutchings, S. C. and Rowlands, D. S. (2016). The sensory acceptance of fibre-enriched cereal foods: a meta-analysis. Int. J. Food Sci. Technol. 51:3-13.

Guarda, A., Rosell, C. M. Benedito, C. and Galotto, M. J. (2004). Different hydrocolloids as bread improvers and antistaling agents. Food Hydrocolloids 18:241247.

Gujral, H. S., Mehta, S., Samra, I. S. and Goyal, P. (2003). Effect of wheat bran, coarse wheat flour and rice flour on the instrumental texture of cookies. Int. J. Food Prop. 6:329-340.

Hayta, M., Ozugur, G., Etgu, H. and Seker, I. T. (2014). Effect of grape (Vitis vinifera L.) pomace on the quality, total phenolic content and anti-radical activity of bread. $J$. Food Process. Preserv. 38:980-986.

Hemdane, S., Jacobs, P. J., Dornez, E., Verspreet, J., Delcour, J. A. and Courtin, C. M. (2016). Wheat (Triticum aestivum L.) bran in bread making: A critical review. Comp. Rev. Food Sci Food Saf. 15:28-42.

Ho, L. H., Aziz, N. A. A. and Azahari, B. (2013). Physico-chemical characteristics and sensory evaluation of wheat bread partially substituted with banana (Musa acuminata X balbisiana cv. Awak) pseudo-stem flour. Food Chem. 139:532-539.

Ho, L. H., Tan, T. C., Aziz, N. A. A. and Bhat, R. (2015). In vitro starch digestibility of bread with banana (Musa acuminata X balbisiana ABB cv. Awak) pseudo-stem flour and hydrocolloids. Food Biosci. 12:10-17. 
Horszwald, A., Julien, H. and Andlauer, W. (2013). Characterisation of Aronia powders obtained by different drying processes. Food Chem. 141:2858-2863.

Hough, G., Wakeling, I., Mucci, A., Chambers, E., Gallardo, I. M. and Alves, L. R. (2006). Number of consumers necessary for sensory acceptability tests. Food Qual. Prefer. 17:522-526.

Hsu, C. L. and Yen, G. C. (2008). Phenolic compounds: Evidence for inhibitory effects against obesity and their underlying molecular signaling mechanisms. Mol. Nutr. Food Res. 52:53-61.

Im, H. W., Suh, B. S., Lee, S. U., Kozukue, N., Ohnisi-Kameyama, M., Levin, C. E. and Friedman, M. (2008). Analysis of phenolic compounds by high-performance liquid chromatography and liquid chromatography/mass spectrometry in potato plant flowers, leaves, stems, and tubers and in home-processed potatoes. J. Agr. Food Chem. 56:33413349 .

Jahurul, M. H. A., Zaidul, I. S. M., Ghafoor, K., Al-Juhaimi, F. Y., Nyam, K. L., Norulaini, N. A. N., Sahena, F. and Mohd Omar, A. K. (2015). Mango (Mangifera indica L.) by-products and their valuable components: A review. Food Chem. 183:173180.

Jenkins, D., Wolever, T., Leeds, A. R., Gassull, M. A., Haisman, P., Dilawari, J., Goff, D. V., Metz, G. L. and Alberti, K. (1978). Dietary fibres, fibre analogues, and glucose tolerance: Importance of viscosity. Br. Med, J. 1:1392-1394.

Juarez-Garcia, E., Agama-Acevedo, E., Sayago-Ayerdi, S. G., Rodriguez-Ambriz, S.L. and Bello-Perez, L. A. (2006). Composition, digestibility and application in breadmaking of banana flour. Plant Food Hum. Nutr. 61:131-137.

Kammerer, D., Claus, A., Carle, R. and Schieber, A. (2004). Polyphenol screening of pomace from red and white grape varieties (Vitis vinifera L.) by HPLC-DAD-MS/MS. J. Agr. Food Chem. 52:4360-4367.

Ktenioudaki, A., O'Shea, N. and Gallagher, E. (2013). Rheological properties of wheat dough supplemented with functional by-products of food processing: Brewer's spent grain and apple pomace. J. Food Eng. 116:362-368.

Knoblich, M., Anderson, B. and Latshaw, D. (2005). Analyses of tomato peel and seed byproducts and their use as a source of carotenoids. J. Sci. Food Agr. 85:1166-1170.

Kohajdova, Z., Karovicova, J. and Jurasova, M. (2013). Influence of grapefruit dietary fibre rich powder on the rheological characteristics of wheat flour dough and on biscuit quality. Acta Aliment. 42:91-101. 
Kohajdova, Z., Karovicova, J., Jurasova, M. and Kukurova, K. (2011). Application of citrus dietary fibre preparations in biscuit production. J. Food Nutr. Res. 50:182-190.

Kohajdova, Z., Karovicova, J., Magala, M. and Kuchtova, V. (2014). Effect of apple pomace powder addition on farinographic properties of wheat dough and biscuits quality. Chem. Pap. 68:1059-1065.

Kurhade, A., Patil, S., Sonawane, S. K., Waghmare, J. S. and Arya, S. S. (2016). Effect of banana peel powder on bioactive constituents and microstructural quality of chapatti: unleavened Indian flat bread. J. Food Meas. Charact. 10:32-41.

Laguna, L., Sanz, T., Sarab, S. and Fiszman, S. M. (2014). Role of fibre morphology in some quality features of fibre-enriched biscuits. Int. J. Food Prop. 17:163-178.

Lam, S., Velikov, K. P. and Velev, O. D. (2014). Pickering stabilization of foams and emulsions with particles of biological origin. Curr. Opin. Colloid Interface Sci. 19:490500 .

Ledesma-Escobar, C. A. and Luque de Castro, M. D. (2014). Towards a comprehensive exploitation of citrus. Trends Food Sci. Technol. 39:63-75.

Maiani, G., Castón, M. J., Catasta, G., Toti, E., Cambrodón, I. G., Bysted, A., GranadoLorencio, F., Olmedilla-Alonso, B., Knuthsen, P., Valoti, M., Böhm, V., MayerMiebach, E., Behsnilian, D., Schlemmer, U. (2009). Carotenoids: Actual knowledge on food sources, intakes, stability and bioavailability and their protective role in humans. Mol. Nutr. Food Res. 53:S194-S218.

Majzoobi, M., Ghavi, F. S., Farahnaky, A., Jamalian, J. and Mesbahi, G. (2011). Effect of tomato pomace powder on the physicochemical properties of flat bread (barbari bread). J. Food Process. Preserv. 35:247-256.

Majzoobi, M., Poor, Z. V., Jamalian, J. and Farahnaky, A. (2016). Improvement of the quality of gluten-free sponge cake using different levels and particle sizes of carrot pomace powder. Int. J. Food Sci. Technol. 51:1369-1377.

Mancebo, C. M., Picón, J. and Gómez, M. (2015a). Effect of flour properties on the quality characteristics of gluten free sugar-snap cookies. LWT - Food Sci. Technol. 64:264-269.

Mancebo, C. M., Rodriguez, P. and Gómez, M. (2016). Assessing rice flour-starchprotein mixtures to produce gluten free sugar-snap cookies. LWT - Food Sci. Technol. 67:127-132. 
Mancebo, C. M., San Miguel, M. A., Martínez, M. M. and Gomez, M. (2015b). Optimisation of rheological properties of gluten-free doughs with HPMC, psyllium and different levels of water. J. Cereal Sci. 61:8-15.

Martinez-Valverde, I., Periago, M. J. and Ros, G. (2000). Nutritional meaning of the phenolic compounds from the diet. Arch. Latinoam. Nutr. 50:5-18.

Matos, M. E. and Rosell, C. M. (2015). Understanding gluten-free dough for reaching breads with physical quality and nutritional balance. J. Sci. Food Agr. 95:653-661.

Mattila, P. and Hellström, J. (2007). Phenolic acids in potatoes, vegetables, and some of their products. J. Food Comp. Anal. 20:152-160.

Mildner-Szkudlarz, S., Bajerska, J., Górnaś, P., Segliņa, D., Pilarska, A. and Jesionowski, T. (2016). Physical and bioactive properties of muffins enriched with raspberry and cranberry pomace powder: a promising application of fruit by-products rich in biocompounds. Plant Foods Hum. Nutr. 71:165-173.

Mildner-Szkudlarz, S. and Bajerska, J. (2013). Protective effect of grape by-productfortified breads against cholesterol/cholic acid diet-induced hypercholesterolaemia in rats. J. Sci. Food Agr. 93:3271-3278.

Mildner-Szkudlarz, S., Siger, A., Szwengiel, A. and Bajerska, J. (2015). Natural compounds from grape by-products enhance nutritive value and reduce formation of CML in model muffins. Food Chem. 172:78-85.

Mildner-Szkudlarz, S., Zawirska-Wojtasiak, R., Szwengiel, A. and Pacynski, M. (2011). Use of grape by-product as a source of dietary fibre and phenolic compounds in sourdough mixed rye bread. Int. J. Food Sci. Technol. 46:1485-1493.

Miller, R. A. (2011). Increased yield of bread containing citrus peel fiber. Cereal Chem. 88:174-178.

Mohamed, A., Xu, J. and Singh, M. (2010). Yeast leavened banana-bread: Formulation, processing, colour and texture analysis. Food Chem. 118:620-626.

Moser, S., Lim, J., Chegeni, M., Wightman, J., Hamaker, B. R. and Ferruzzi, M. G. (2016). Concord and niagara grape juice and their phenolics modify intestinal glucose transport in a coupled in vitro digestion/caco-2 human intestinal model. Nutrients 8:414. Mrabet, A., Rodriguez-Gutierrez, G., Rodriguez-Arcos, R., Guillen-Bejarano, R., Ferchichi, A., Sindic, M. and Jimenez-Araujo, A. (2016). Quality characteristics and antioxidant properties of muffins enriched with date fruit (Phoenix dactylifera 1.) fiber concentrates. J. Food Qual. 39:237-244. 
Muller, L., Caris-Veyrat, C., Lowe, G. and Bohm, V. (2016). Lycopene and its antioxidant role in the prevention of cardiovascular diseases: A critical review. Crit. Rev. Food Sci. Nutr. 56:1868-1879.

Naknaen, P., Itthisoponkul, T., Sondee, A. and Angsombat, N. (2016). Utilization of watermelon rind waste as a potential source of dietary fiber to improve health promoting properties and reduce glycemic index for cookie making. Food Sci. Biotechnol. 25:415-424.

Nawirska, A. and Kwasniewska, M. (2005). Dietary fibre fractions from fruit and vegetable processing waste. Food Chem. 91:221-225.

Nour, V., Ionica, M. E. and Trandafir, I. (2015). Bread enriched in lycopene and other bioactive compounds by addition of dry tomato waste. J. Food Sci. Technol. 52:82608267.

Orr, P. H., Toma, R. B., Munson, S. T. and D’Appolonia, B. (1982). Sensory evaluation of breads containing various levels of potato peel. Am. Potato J. 59:605-611.

O'Shea, N., Arendt, E. K. and Gallagher, E. (2012). Dietary fibre and phytochemical characteristics of fruit and vegetable by-products and their recent applications as novel ingredients in food products. Innov. Food Sci. Emerg. Technol. 16:1-10.

O'Shea, N., Doran, L., Auty, M., Arendt, E. and Gallagher, E. (2013). The rheology, microstructure and sensory characteristics of a gluten-free bread formulation enhanced with orange pomace. Food Funct. 4:1856-1863.

O'Shea, N., Rossle, C., Arendt, E. and Gallagher, E. (2015). Modelling the effects of orange pomace using response surface design for gluten-free bread baking. Food Chem. 166:223-230.

Padam, B. S., Tin, H. S., Chye, F. Y. and Abdullah, M. I. (2014). Banana by-products: an under-utilized renewable food biomass with great potential. J. Food Sci. Technol. 51:3527-3545.

Pareyt, B. and Delcour, J. A. (2008). The role of wheat flour constituents, sugar, and fat in low moisture cereal based products: a review on sugar-snap cookies. Crit. Rev. Food Sci. Nutr. 48:824-839.

Pathak, D., Majumdar, J., Raychaudhuri, U. and Chakraborty, R. (2016). Characterization of physicochemical properties in whole wheat bread after incorporation of ripe mango peel. J. Food Meas. Charact. 10:554-561. 
Padayachee, A., Day, L., Howella, K. and Gidley M. J. (2017). Complexity and health functionality of plant cell wall fibers from fruits and vegetables. Crit. Rev. Food Sci. Nutr. 57:59-81.

Perez-Jimenez, J., Neveu, V., Vos, F. and Scalbert, A. (2010). Identification of the 100 richest dietary sources of polyphenols: an application of the Phenol-Explorer database. Eur. J. Clin. Nutr. 64:S112-S120.

Quiles, A., Campbell, G. M., Struck, S., Rohm, H. and Hernando, I. (2017). Fiber from fruit pomace: A review of applications in cereal-based products. Food Rev. Int. doi:10.1080/87559129.2016.1261299

Rabetafikaa, H. N., Bchirb, B., Bleckerb, C. and Richel, A. (2014). Fractionation of apple by-products as source of new ingredients: Current situation and perspectives. Trends Food Sci. Technol. 40:99-114.

Ramirez-Maganda, J., Blancas-Benitez, F. J., Zamora-Gasga, V. M., Garcia-Magana, M. D. L., Bello-Perez, L. A., Tovar, J. and Sayago-Ayerdi, S. G. (2015). Nutritional properties and phenolic content of a bakery product substituted with a mango (Mangifera indica) 'Ataulfo' processing by-product. Food Res. Int. 73:117-123.

Romero-Lopez, M. R., Osorio-Diaz, P., Bello-Perez, L. A., Tovar, J. and BernardinoNicanor, A. (2011). Fiber concentrate from orange (Citrus sinensis L.) bagase: Characterization and application as bakery product ingredient. Int. J. Mol. Sci. 12:21742186.

Ronda, F., Quilez, J., Pando, V. and Roos, Y. H. (2014). Fermentation time and fiber effects on recrystallization of starch components and staling of bread from frozen partbaked bread. J. Food Eng. 131:116-123.

Rosell, C.M. and Santos, E. (2010). Impact of fibers on physical characteristics of fresh and staled bake off bread. J. Food Eng. 98:273-281.

Rosell, C. M., Rojas, J. A. and Benedito de Barber, C. (2001). Influence of hydrocolloids on dough rheology and bread quality. Food Hydrocolloids 15:75-81.

Rosell, C. M., Santos, E. and Collar, C. (2006). Mixing properties of fibre-enriched wheat bread doughs: A response surface methodology study. Eur. Food Res. Technol. 223:333-340.

Rupasinghe, H. P. V., Wang, L. X., Huber, G. M. and Pitts, N. L. (2008). Effect of baking on dietary fibre and phenolics of muffins incorporated with apple skin powder. Food Chem. 107:1217-1224. 
Rupasinghe, H. P. V., Wang, L. X., Pitts, N. L. and Astatkie, T. (2009). Baking and sensory characteristics of muffins incorporated with apple skin powder. J. Food Qual. 32:685-694.

Russ, W. and Meyer-Pittroff, R. (2004). Utilizing waste products from the food production and processing industries. Crit. Rev. Food Sci. Nutr. 44:57-62.

Salgado, J. M., Rodrigues, B. S., Donado-Pestana, C. M., Dias, C. T. D. and Morzelle, M. C. (2011). Cupuassu (Theobroma grandiflorum) peel as potential source of dietary fiber and phytochemicals in whole-bread preparations. Plant Foods Hum. Nutr. 66:384390

Santos, E., Rosell C. M. and Collar, C. (2008). Gelatinization and retrogradation kinetics of high-fiber wheat flour blends: a calorimetric approach. Cereal Chem. 85:457-465.

Šaponjac, V. T., Ćetković, G., Čanadanović-Brunet, J., Pajin, B., Djilas, S., Petrović, J., Lončarević, I., Stajčić, S. and Vulić, J. (2016). Sour cherry pomace extract encapsulated in whey and soy proteins: Incorporation in cookies. Food Chem. 207:27-33.

Sarawong, C., Gutierrez, Z. R., Berghofer, E. and Schoenlechner, R. (2014). Effect of green plantain flour addition to gluten-free bread on functional bread properties and resistant starch content. Int. J. Food Sci. Technol. 49:1825-1833.

Šarić, B., Mišan, A., Mandić, A., Nedeljković, N., Pojić, M., Pestorić, M. and Đilas, S. (2016). Valorisation of raspberry and blueberry pomace through the formulation of value-added gluten-free cookies. J. Food Sci. Technol. 53:1140-1150.

Scalbert, A., Manach, C., Morand, C., Remesy, C. and Jimenez, L. (2005). Dietary polyphenols and the prevention of diseases. Crit. Rev. Food. Sci. Nutr. 45:287-306.

Scazzina, F., Siebenhandl-Ehn, S. and Pellegrini, N. (2013). The effect of dietary fibre on reducing the glycaemic index of bread. Br. J. Nutr. 109:1163-1174.

Schieber, A., Stintzing, F. C. and Carle, R. (2001). By-products of plant food processing as a source of functional compounds - recent developments. Trends Food Sci. Technol. 12:401-413.

Seguchi, M., Tabara, A., Iseki, K., Takeuchi, M. and Nakamura, C. (2014). Development of gluten-free bread baked with banana (Musa spp.) flour. Food Sci. Technol. Res. 20:613-619.

Segundo, C., Román, L., Gómez, M. and Martínez, M. M. (2017). Mechanically fractionated flour isolated from green bananas (M. cavendishii var. nanica) as a tool to 
increase the dietary fiber and phytochemical bioactivity of layer and sponge cakes. Food Chem. 219:240-248.

Shalini, R. and Gupta, D. K. (2010). Utilization of pomace from apple processing industries: A review. J. Food Sci. Technol. 47:365-371.

Shyu, Y. S., Lu, T. C. and Lin, C. C. (2014). Functional analysis of unfermented and fermented citrus peels and physical properties of citrus peel-added doughs for bread making. J. Food Sci. Technol. 51:3803-3811.

Sojka, M., Klimczak, E., Macierzynski, J. and Kołodziejczyk, K. (2013b). Nutrient and polyphenolic composition of industrial strawberry press cake. Eur. Food Res. Technol. 237:995-1007.

Sojka, M., Kołodziejczyk, K. and Milala, J. (2013a). Polyphenolic and basic chemical composition of black chokeberry industrial by-products. Ind. Crops Prod. 51:77-86.

Srivastava, P., Indrani, D. and Singh, R. P. (2014). Effect of dried pomegranate (Punica granatum) peel powder (DPPP) on textural, organoleptic and nutritional characteristics of biscuits. Int. J. Food Sci. Nutr. 65:827-833.

Stauffer, C. E. (1990). Functional additives for bakery foods. Van Nostrand Reinhold, New York (USA).

Stoll, L., Flores, S. H. and Thys, R. C. S. (2015). Citrus peel fiber and its application as a fat substitute in loaf bread. Ciencia Rural 45:567-573.

Struck, S., Plaza, M., Turner, C. and Rohm, H. (2016). Berry pomace - a review of processing and chemical analysis of its polyphenols. Int. J. Food Sci. Technol. 51:13051318.

Sudha, M. L., Vetrimani, R., and Leelavathi, K. (2007). Influence of fibre from different cereals on the rheological characteristics of wheat flour dough and on biscuit quality. Food Chem. 100:1365-1370.

Sudha, M. L., Dharmesh, S. M., Pynam, H., Bhimangouder, S. V., Eipson, S. W., Somasundaram, R. and Nanjarajurs, S. M. (2016). Antioxidant and cyto/DNA protective properties of apple pomace enriched bakery products. J. Food Sci. Technol. 53:1909-1918.

Sudha, M. L., Indumathi, K., Sumanth, M. S., Rajarathnam, S. and Shashirekha, M. N. (2015). Mango pulp fibre waste: characterization and utilization as a bakery product ingredient. J. Food Meas. Charact. 9:382-388. 
Sun, T., Simon, P. W. and Tanumihardjo, S. A. (2009). Antioxidant phytochemicals and antioxidant capacity of biofortified carrots (Daucus carota L.) of various colors. J. Agr. Food Chem. 57:4142-4147.

Surles, R. L., Weng, N., Simon, P. W. and Tanumihardjo, S. A. (2004). Carotenoid profiles and consumer sensory evaluation of specialty carrots (Daucus carota, L.) of various colors. J. Agr. Food Chem. 52:3417-3421.

Swieca, M., Gawlik-Dziki, U., Dziki, D., Baraniak, B and Czyz, J. (2013). The influence of protein-flavonoid interactions on protein digestibility in vitro and the antioxidant quality of breads enriched with onion skin. Food Chem. 141:451-458.

Tańska, M., Roszkowska, B., Czaplicki, S., Borowska, E. J., Bojarska, J. and Dąbrowska, A. (2016). Effect of fruit pomace addition on shortbread cookies to improve their physical and nutritional values. Plant Foods Hum. Nutr. 71:307-313.

Torres-León, C., Rojas, R., Contreras-Esquivel, J. C., Serna-Cock, L., Belmares-Cerda, R. E. and Aguilar, C. N. (2016). Mango seed: Functional and nutritional properties. Trends Food Sci. Technol. 55:109-117.

Turksoy, S. and Ozkaya, B. (2011). Pumpkin and carrot pomace powders as a source of dietary fiber and their effects on the mixing properties of wheat flour dough and cookie quality. Food Sci. Technol. Res. 17:545-553.

Upadhyay, A., Sharma, H. K. and Sarkar, B. C. (2008). Characterization and dehydration kinetics of carrot pomace. Agric. Eng. Int. 10:1-9.

Verspreet, J., Damen, B., Broekaert, W. F., Verbeke, K., Delcour, J. A., Courtin, C. M. (2016). A critical look at prebiotics within the dietary fiber concept. Annu. Rev. Food Sci. Technol. 7:167-90.

Waghmare, A. G. and Arya, S. S. (2014). Use of fruit by-products in the preparation of hypoglycemic thepla: Indian unleavened vegetable flat bread. J. Food Process. Preserv. 38:1198-1206.

Walker, R., Tseng, A., Cavender, G., Ross, A., Zhao, Y. Y. (2014). Physicochemical, nutritional, and sensory qualities of wine grape pomace fortified baked goods. J. Food Sci. 79:S1811-S1822.

Wu, M. Y. and Shiau, S. Y. (2015). Effect of the amount and particle size of pineapple peel fiber on dough rheology and steamed bread quality. J. Food Process. Preserv. 39:549-558.

Yamazaki, W. T. and Donelson, D. H. (1972). The relationship between flour particle size and cake-volume potential among eastern soft wheats. Cereal Chem. 49:649-653. 
Younis, K., Islam, R., Jahan, K., Kundu, M. and Ray, A. (2016). Investigating the effect of mosambi (Citrus limetta) peel powder on physicochemical and sensory properties of cookies. Qual. Assur. Saf. Crops Foods 8:393-398.

Yu, Y. and Ahmedna, M. (2013). Functional components of grape pomace: their composition, biological properties and potential applications. Int. J. Food Sci. Technol. 48:221-237.

Zhang, P., Whistler, R. L., BeMiller, J. N. and Hamaker, B. R. (2005). Banana starch: production, physicochemical properties and digestibility - A review. Carbohydr. Polym. 59:443-458.

Zhang, P. and Hamaker, B. R. (2012). Banana starch structure and digestibility. Carbohydr. Polym. 87:1552-1558. 
Fig. 1. Literature search of the last 20 years on the topics "by-product and bread" and "by-product and biscuit or cookie or muffin". a) number of publications per year; b) number of citations per year. Source: Web of Science Core Collection, until February 1 st, 2017

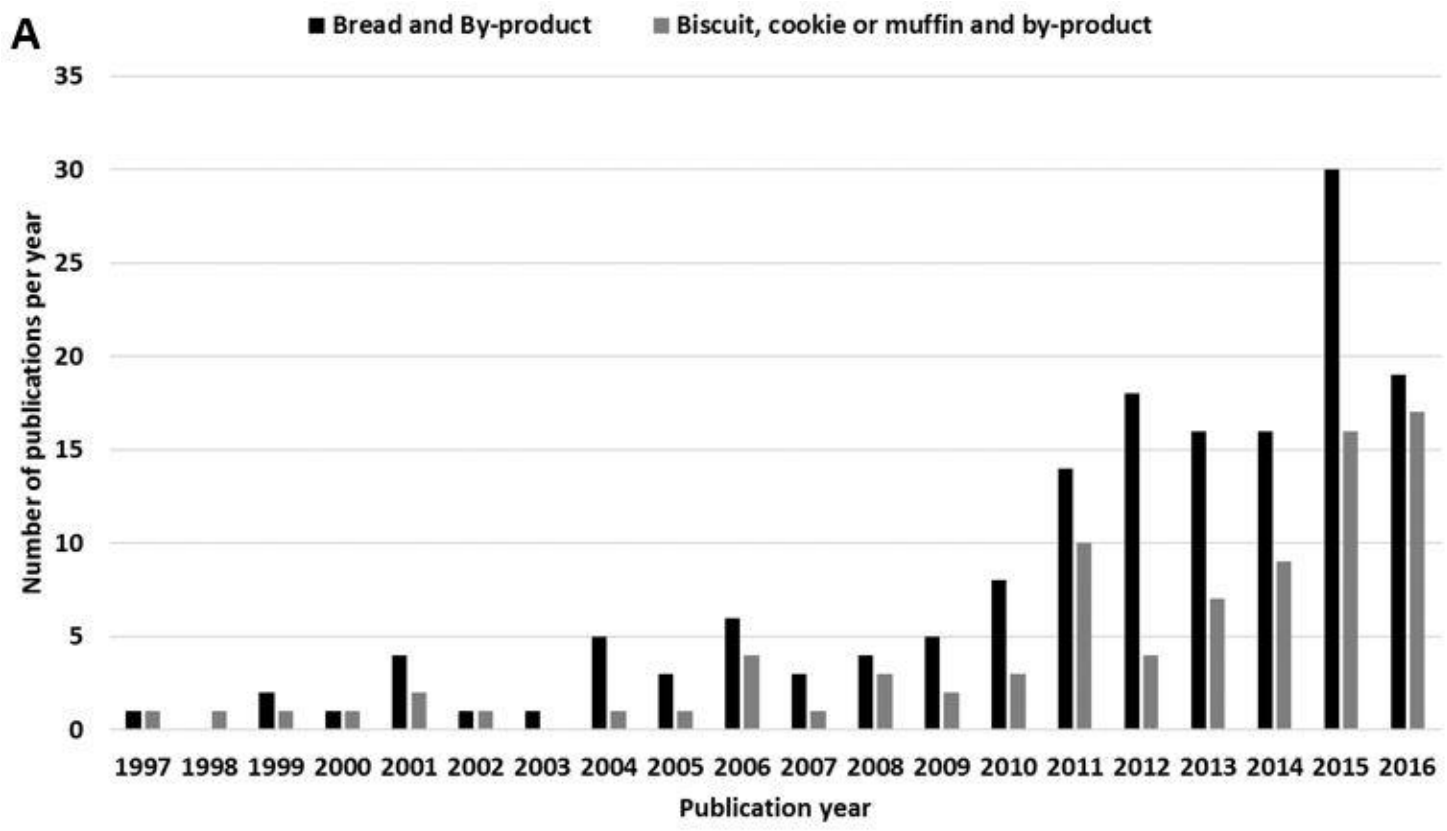

B $350-\longrightarrow$

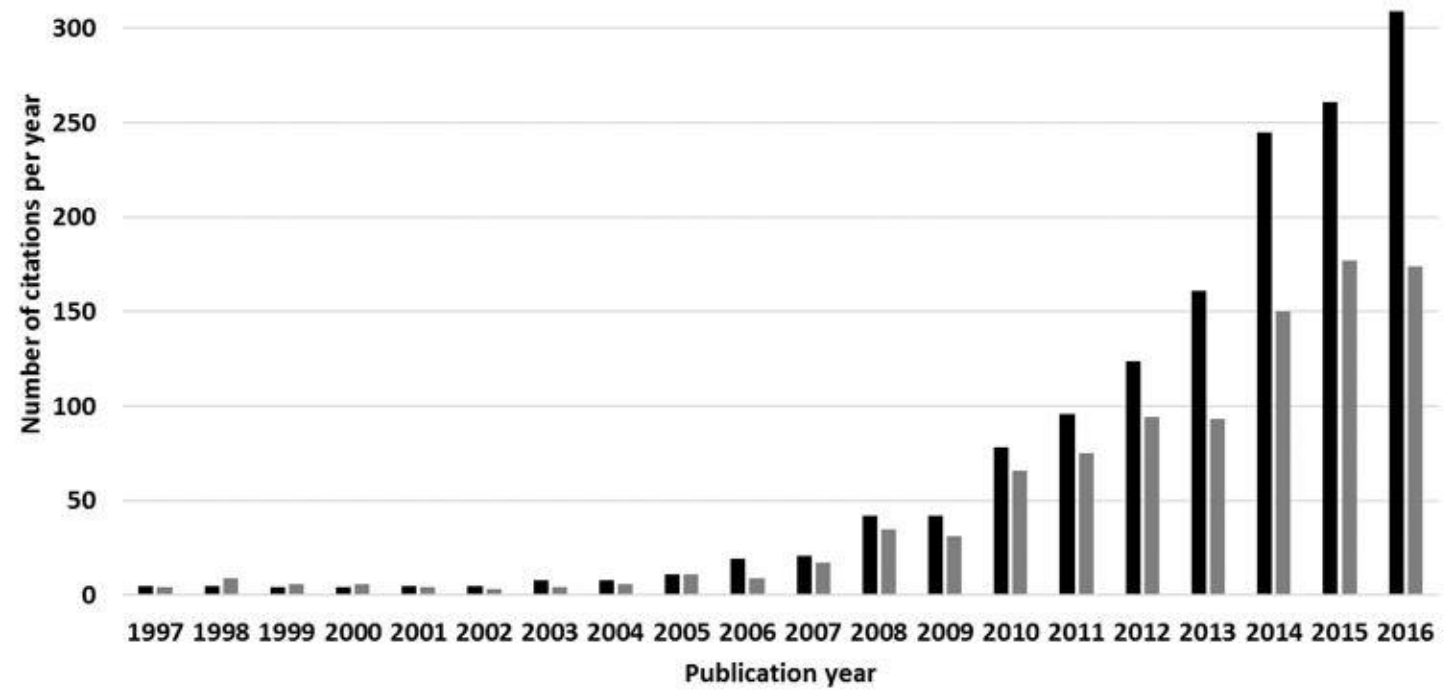


Table 1: A partial listing of papers on practical uses of fruit and vegetable by-products in breads ${ }^{\mathrm{a}}$

\begin{tabular}{|c|c|c|c|c|c|c|c|c|c|c|}
\hline Reference & By-product & Baked good & $\begin{array}{l}\text { Max } \\
\%^{b}\end{array}$ & $\begin{array}{c}\text { Dough } \\
\text { assessment }^{\mathrm{d}}\end{array}$ & $\begin{array}{l}\text { Bread } \\
\text { quality }^{\mathrm{e}}\end{array}$ & Fiber & Polyphenols $^{\mathrm{f}}$ & $\mathrm{AC}^{\mathrm{g}}$ & GI $^{\text {h }}$ & $\begin{array}{c}\text { Other } \\
\text { nutritional } \\
\text { analyses }\end{array}$ \\
\hline Altunkaya et al., 2013 & Pomegranate peel & Bread & 10 & & $\mathrm{C}, \mathrm{Se}$ & & & & & \\
\hline Bchir et al., 2014 & $\begin{array}{l}\text { Pear, apple and date } \\
\text { pomace }\end{array}$ & Bread & $\begin{array}{l}2 \% \\
\text { fiber }^{\mathrm{c}}\end{array}$ & $\mathrm{F}, \mathrm{A}, \mathrm{Vi}$ & $\mathrm{V}, \mathrm{T}, \mathrm{C}$ & & & & & \\
\hline Bhol et al., 2016 & Pomegranate pomace & Bread & 15 & & $\mathrm{~V}, \mathrm{Se}$ & & & & & \\
\hline Chareonthaikij et al., 2016 & $\begin{array}{l}\text { Pineapple pomace } \\
\text { fiber }\end{array}$ & Bread & 10 & $\mathrm{~F}, \mathrm{Vi}$ & $\mathrm{V}, \mathrm{T}, \mathrm{C}, \mathrm{Se}$ & & & & & \\
\hline Curti et al., 2016 & Potato peel fiber & Bread & 0.4 & & $\mathrm{~T}, \mathrm{C}, \mathrm{S}$ & & & & & \\
\hline Gawlik-Dziki et al., 2013 & Onion skin & Bread & 5 & & $\mathrm{Se}$ & & Quercetin & & & $\begin{array}{c}\text { in vitro } \\
\text { antioxidant } \\
\text { absorption }\end{array}$ \\
\hline Gawlik-Dziki et al., 2015 & Onion skin & Bread & 5 & & & & & & & $\begin{array}{c}\text { biological activity } \\
\text { on cancer cells }\end{array}$ \\
\hline Hayta et al., 2014 & Grape pomace & Bread & 10 & & $\mathrm{~V}, \mathrm{~T}, \mathrm{C}, \mathrm{S}, \mathrm{Se}$ & & & & & \\
\hline Ho et al., 2013 & Banana pseudo-stem & Bread & 10 & & $\mathrm{~V}, \mathrm{C}, \mathrm{Se}$ & & & & & \\
\hline
\end{tabular}




\begin{tabular}{|c|c|c|c|c|c|c|c|}
\hline & flour & & & & & & \\
\hline Juarez-García et al., 2006 & Unripe banana flour & Bread & 100 & & & & \\
\hline $\begin{array}{l}\text { Mildner-Szkudlarz and } \\
\text { Bajerska, } 2013\end{array}$ & Grape by-products & Bread & 10 & & $\mathrm{Se}$ & $\begin{array}{c}\text { Gallic acid } \\
\gamma \text {-resorcylic acid } \\
\text { Catechin } \\
\text { Procyanidin B1 } \\
\text { Procyanidin B2 } \\
\text { Epicatechin } \\
\text { p-coumaric acid } \\
\text { trans-Ferulic acid }\end{array}$ & $\begin{array}{c}\text { Food intake, } \\
\text { faecal bulking } \\
\text { and fat and } \\
\text { protein excretion } \\
\text { in rats } \\
\text { Postpandrial } \\
\text { serum } \\
\text { biochemical } \\
\text { parameters }\end{array}$ \\
\hline Miller, 2011 & Citrus peel fiber & Bread & 2,5 & $\mathrm{~F}, \mathrm{~A}$ & $\mathrm{~V}, \mathrm{~T}, \mathrm{C}, \mathrm{S}$ & & \\
\hline Mohamed et al., 2010 & Banana flour & Bread & 30 & $\mathrm{~F}$ & $\mathrm{~V}, \mathrm{~T}, \mathrm{C}, \mathrm{S}$ & & \\
\hline Nour et al., 2015 & Dry tomato waste & Bread & 10 & & $\mathrm{~V}, \mathrm{~T}, \mathrm{Se}$ & $\begin{array}{l}\text { Lycopene } \\
\beta \text {-carotene }\end{array}$ & \\
\hline Orr et al., 1982 & Potato peel & Bread & 15 & & $\mathrm{Se}$ & & \\
\hline Shyu et al., 2014 & Citrus peel & Bread & 6 & $\mathrm{~F}$ & $\mathrm{Se}$ & & \\
\hline Stoll et al., 2015 & Orange peel fiber & Bread & 5 & & $\mathrm{~V}, \mathrm{C}, \mathrm{Se}$ & & \\
\hline
\end{tabular}




\begin{tabular}{|c|c|c|c|c|c|c|c|}
\hline Swieca et al., 2013 & Onion skin & Bread & 4 & & & Total flavonoids & $\begin{array}{c}\text { in vitro protein } \\
\text { digestibility }\end{array}$ \\
\hline Walker at al., 2014 & Wine grape pomace & Bread & 15 & $\mathrm{~F}$ & $\mathrm{~V}, \mathrm{~T}, \mathrm{C}, \mathrm{Se}$ & & \\
\hline Ktenioudaki et al., 2013 & Apple pomace & Bread dough & 35 & $\mathrm{~F}, \mathrm{~A}, \mathrm{R}, \mathrm{Fe}$ & & & \\
\hline Pathak et al., 2016 & Ripe mango peel & Whole bread & 5 & $\mathrm{R}$ & $\mathrm{V}, \mathrm{T}, \mathrm{C}, \mathrm{Se}$ & & \\
\hline Salgado et al., 2011 & Cupuassu peel & Whole Bread & 9 & & $\mathrm{~V}, \mathrm{C}$ & & \\
\hline $\begin{array}{l}\text { Mildner-Szkudlarz et al., } \\
2011\end{array}$ & Grape by-products & Rye Bread & 10 & & $\mathrm{~T}, \mathrm{Se}$ & $\begin{array}{c}\text { Gallic acid } \\
\gamma \text {-resorcylic acid } \\
\text { Catechin } \\
\text { Procyanidin B1 } \\
\text { Procyanidin B2 } \\
\text { Epicatechin } \\
\text { p-coumaric acid } \\
\text { trans-Ferulic acid } \\
\text { Caffeic acid } \\
\text { Sinapic acid } \\
\text { Quercetin-3- } \beta-D- \\
\text { glucoside }\end{array}$ & \\
\hline
\end{tabular}




\begin{tabular}{|c|c|c|c|c|c|c|c|}
\hline & & & & & & $\begin{array}{l}\text { Myricetin } \\
\text { Quercetin }\end{array}$ & \\
\hline Majzoobi et al., 2011 & Tomato pomace & Flat bread & 7 & $\mathrm{~F}$ & T,C,S, Se & & \\
\hline Waghmare and Arya, 2014 & $\begin{array}{l}\text { apple pomaces, } \\
\text { papaya peels and } \\
\text { watermelon rinds }\end{array}$ & Flat Bread & 9 & $\mathrm{~T}$ & $\mathrm{C}, \mathrm{Se}$ & & \\
\hline Kurhade et al., 2016 & Banana peel & Chapatti & 20 & $\mathrm{~T}$ & $\mathrm{~T}, \mathrm{M}, \mathrm{Se}$ & Total Flavonoids & \\
\hline Fu et al., 2015 & Lemon pomace fiber & Steamed bread & 9 & $\bar{A}$ & $\mathrm{~V}, \mathrm{~T}, \mathrm{Se}$ & & \\
\hline Wu and Shiau, 2015 & Pineapple peel fiber & Steamed bread & 15 & A & $\mathrm{V}, \mathrm{T}, \mathrm{C}, \mathrm{Se}$ & & \\
\hline Sudha et al., 2016 & Apple pomace & Buns & 20 & & V,T,C, Se & $\begin{array}{c}\text { Gallic acid } \\
\text { Catechin } \\
\text { Chlorogenic acid } \\
\text { Caffeic acid } \\
\text { Epicatechin } \\
\text { p-coumaric acid } \\
\text { Ferulic acid } \\
\text { Protocatechuic acid } \\
\text { Quercetin }\end{array}$ & $\begin{array}{c}\text { Cytoprotective } \\
\text { ability on red } \\
\text { blood cells } \\
\text { Protectivity } \\
\text { against buccal } \\
\text { mammalian cells } \\
\text { DNA protective } \\
\text { ability }\end{array}$ \\
\hline
\end{tabular}




\begin{tabular}{|l|l|l|c|c|c|c|c|c|}
\hline Aguilar et al., 2015 & Tiger nut by-product & $\begin{array}{l}\text { Gluten-free } \\
\text { bread }\end{array}$ & 5 & R, Fe & V,T,C,S, Se & & \\
\hline O'Shea et al., 2015 & Orange pomace & $\begin{array}{l}\text { Gluten-free } \\
\text { bread }\end{array}$ & 8 & & V,T,S & & \\
\hline O'Shea et al., 2013 & Orange pomace & $\begin{array}{l}\text { Gluten-free } \\
\text { bread }\end{array}$ & 5.5 & F,Vi,R,M & M, Se & & & \\
\hline Sarawong et al., 2014 & Unripe banana flour & Gluten-free & 35 & & V,T,C & & & \\
\hline Seguchi et al., 2014 & $\begin{array}{l}\text { Unripe and ripe } \\
\text { banana flour }\end{array}$ & Gluten-free \\
bread & 50 & & & V,C & & & \\
\hline
\end{tabular}

${ }^{\text {a }}$ Shaded cells indicates that the corresponding test described for each column was performed

${ }^{\mathrm{b}}$ Maximum percent of flour replacement by the fruit and vegetable by-product

${ }^{\mathrm{c}}$ The authors replaced flour with a by-product until $2 \%$ content of fiber was obtained in the final bread

${ }^{\mathrm{d}}$ Physical characteristics of the dough as evaluated by farinograph or mixolab (F), alveograph or kieffer probe (A), fundamental rheology (R),

texture (T), RVA or viscoamilograph for a dough/batter-like mix (Vi), rheofermentometer (Fe) or microstructure (M)

${ }^{\mathrm{e}}$ Physical quality of breads as evaluated by their volume $(\mathrm{V})$, texture $(\mathrm{T})$, color $(\mathrm{C})$, staling $(\mathrm{S})$, microstructure $(\mathrm{M})$ or sensory analysis $(\mathrm{Se})$ 
${ }^{\mathrm{f}}$ In most studies, polyphenols were analyzed following the Folin-Ciocalteau method for the total phenolic content. Studies containing other additional characterization for bioactive compounds are also described in the table.

${ }^{\mathrm{g}}$ Antioxidant capacity

${ }^{\mathrm{h}}$ Glycemic index determined either in vitro or in vivo 
Table 2: A partial listing of papers on practical uses of fruit and vegetable by-products on cakes and cookies ${ }^{\mathrm{a}}$

\begin{tabular}{|c|c|c|c|c|c|c|c|c|c|c|}
\hline Reference & By-product & Baked good & $\begin{array}{c}\text { Max } \\
\%^{b}\end{array}$ & $\begin{array}{c}\text { Dough } \\
\text { assessment }^{\mathrm{c}}\end{array}$ & $\begin{array}{l}\text { Product } \\
\text { quality }^{\mathrm{d}}\end{array}$ & Fiber & Polyphenols $^{\mathrm{e}}$ & $\mathbf{A C}^{\mathrm{f}}$ & $\mathbf{G I}^{\mathrm{g}}$ & $\begin{array}{c}\text { Other nutritional } \\
\text { analyses }\end{array}$ \\
\hline Aziah et al., 2011 & $\begin{array}{l}\text { Mango pulp and } \\
\text { peel }\end{array}$ & Sponge cake & 30 & & $\mathrm{~V}, \mathrm{~T}, \mathrm{C}, \mathrm{Se}$ & & & & & \\
\hline Majzoobi et al., 2016 & Carrot pomace & Sponge cake & 30 & $\rho, \mathrm{V}, \mathrm{T}$ & $\mathrm{V}, \mathrm{T}, \mathrm{Se}$ & & & & & \\
\hline Segundo et al., 2016 & $\begin{array}{l}\text { Unripe banana } \\
\text { flour }\end{array}$ & $\begin{array}{l}\text { Layer and } \\
\text { sponge cake }\end{array}$ & & $\rho, \mathrm{V}$ & $\mathrm{V}, \mathrm{T}, \mathrm{Se}$ & & & & & \\
\hline $\begin{array}{l}\text { Arora and Camire, } \\
1994\end{array}$ & Potato peel & Muffins & 25 & & $\mathrm{H}, \mathrm{T}, \mathrm{C}, \mathrm{Se}$ & & & & & \\
\hline Bajerska et al., 2016 & $\begin{array}{l}\text { Sour Cherry } \\
\text { pomace }\end{array}$ & Muffins & 40 & & $\mathrm{Se}$ & & $\begin{array}{l}\text { Cyanidin-3-O-glucosyl- } \\
\text { rutinoside } \\
\text { Cyanidin-3-O-glucoside } \\
\text { Cyanidin-3-O-rutinoside } \\
\text { Quercetin-3-O-rutinoside } \\
\text { Kaempferol-3-O-rutinoside } \\
\text { Isorhamnetin-3-O-rutinoside } \\
\text { Neochlorogenic acid }\end{array}$ & & & $\begin{array}{l}\text { In vivo glycemic } \\
\text { response } \\
\text { Satiety } \\
\text { Subsequent pasta } \\
\text { meal and energy } \\
\text { intake }\end{array}$ \\
\hline
\end{tabular}




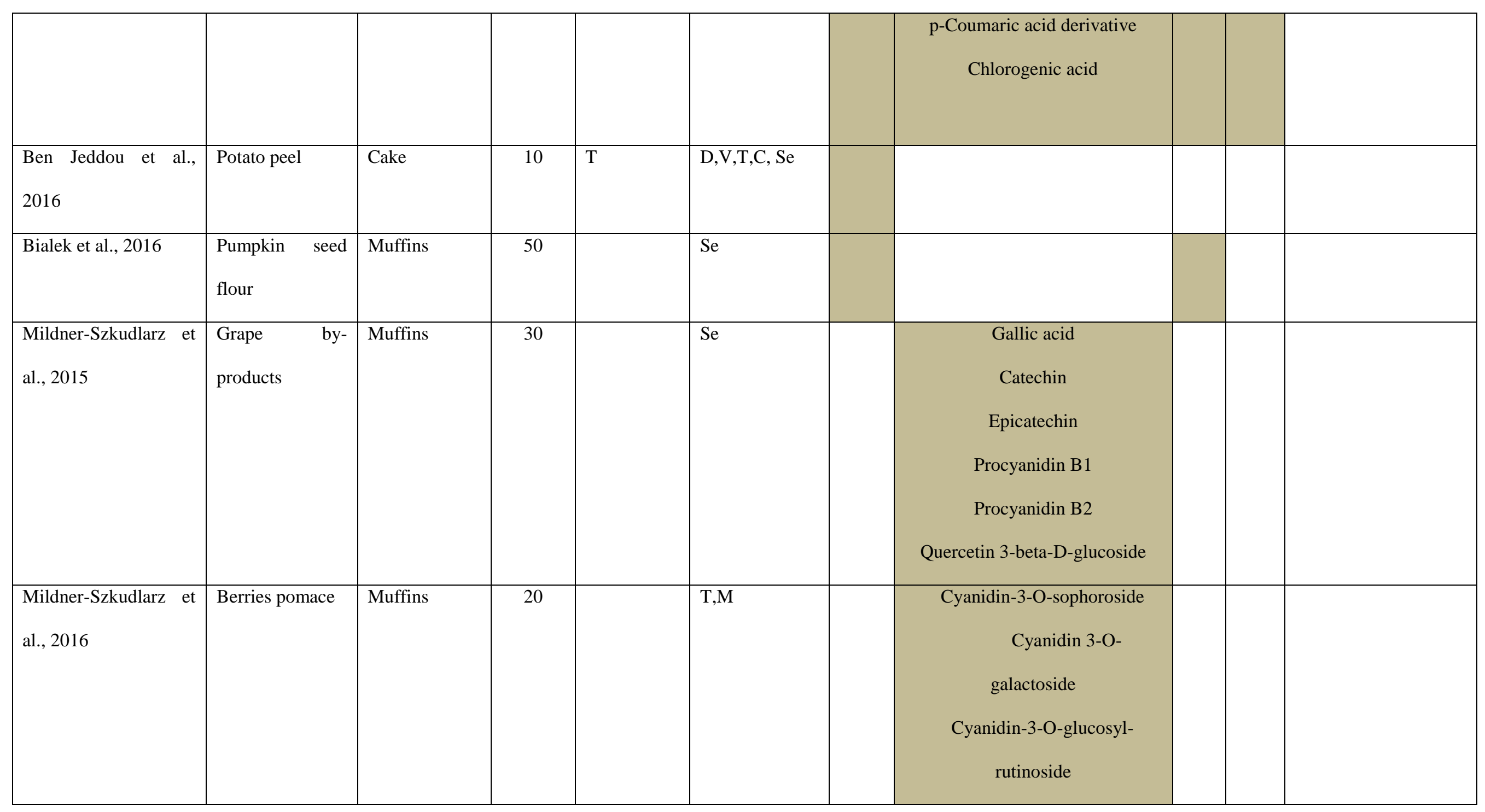




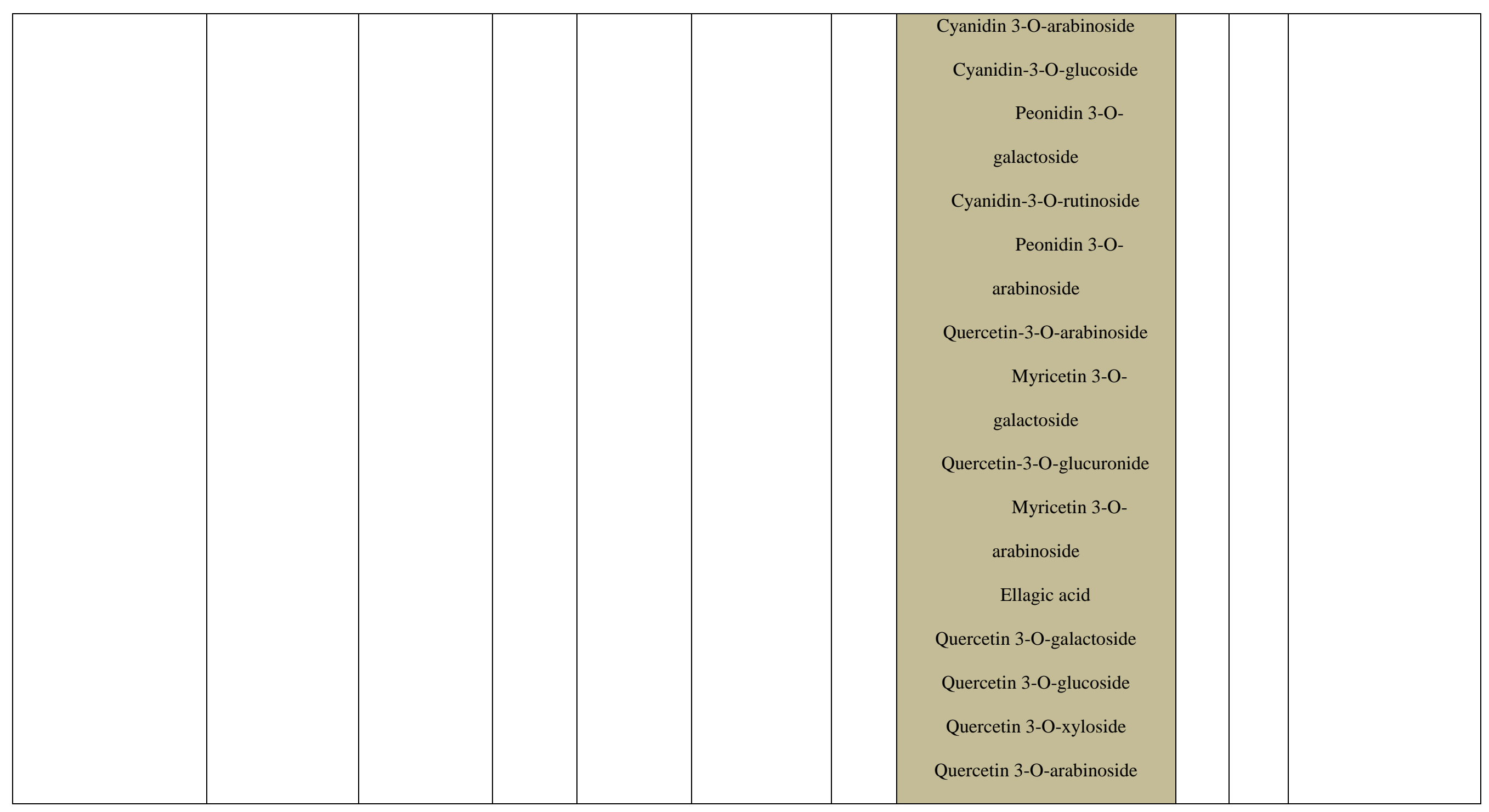




\begin{tabular}{|c|c|c|c|c|c|}
\hline & & & & & $\begin{array}{c}\text { Quercetin 3-O- } \\
\text { rhamnoside } \\
\text { Syringetin 3-O-galactoside }\end{array}$ \\
\hline Mrabet et al., 2016 & Date fruit fiber & Muffins & 5 & V,T,C, Se & \\
\hline $\begin{array}{l}\text { Ramirez-Maganda et } \\
\text { al., } 2015\end{array}$ & Mango paste & Muffins & 75 & $\mathrm{Se}$ & $\begin{array}{c}\text { Gallic acid } \\
\text { Chlorogenic acid } \\
\text { Caffeic acid } \\
\text { Ferulic acid } \\
\text { Hydroxycinnamic acid }\end{array}$ \\
\hline $\begin{array}{l}\text { Romero-López et al., } \\
2011\end{array}$ & $\begin{array}{l}\text { Orange pomace } \\
\text { fibre }\end{array}$ & Muffins & 15 & & \\
\hline $\begin{array}{l}\text { Rupasinghe et al., } \\
2009\end{array}$ & Apple skin & Muffins & 32 & $\mathrm{H}, \mathrm{T}, \mathrm{C}, \mathrm{Se}$ & \\
\hline $\begin{array}{l}\text { Rupasinghe et al., } \\
2008\end{array}$ & Apple skin & Muffins & 32 & & $\begin{array}{l}\text { Quercetin-3- } \\
\text { galactoside } \\
\text { Quercetin-3- } \\
\text { glucoside } \\
\text { Quercetin-3- }\end{array}$ \\
\hline
\end{tabular}




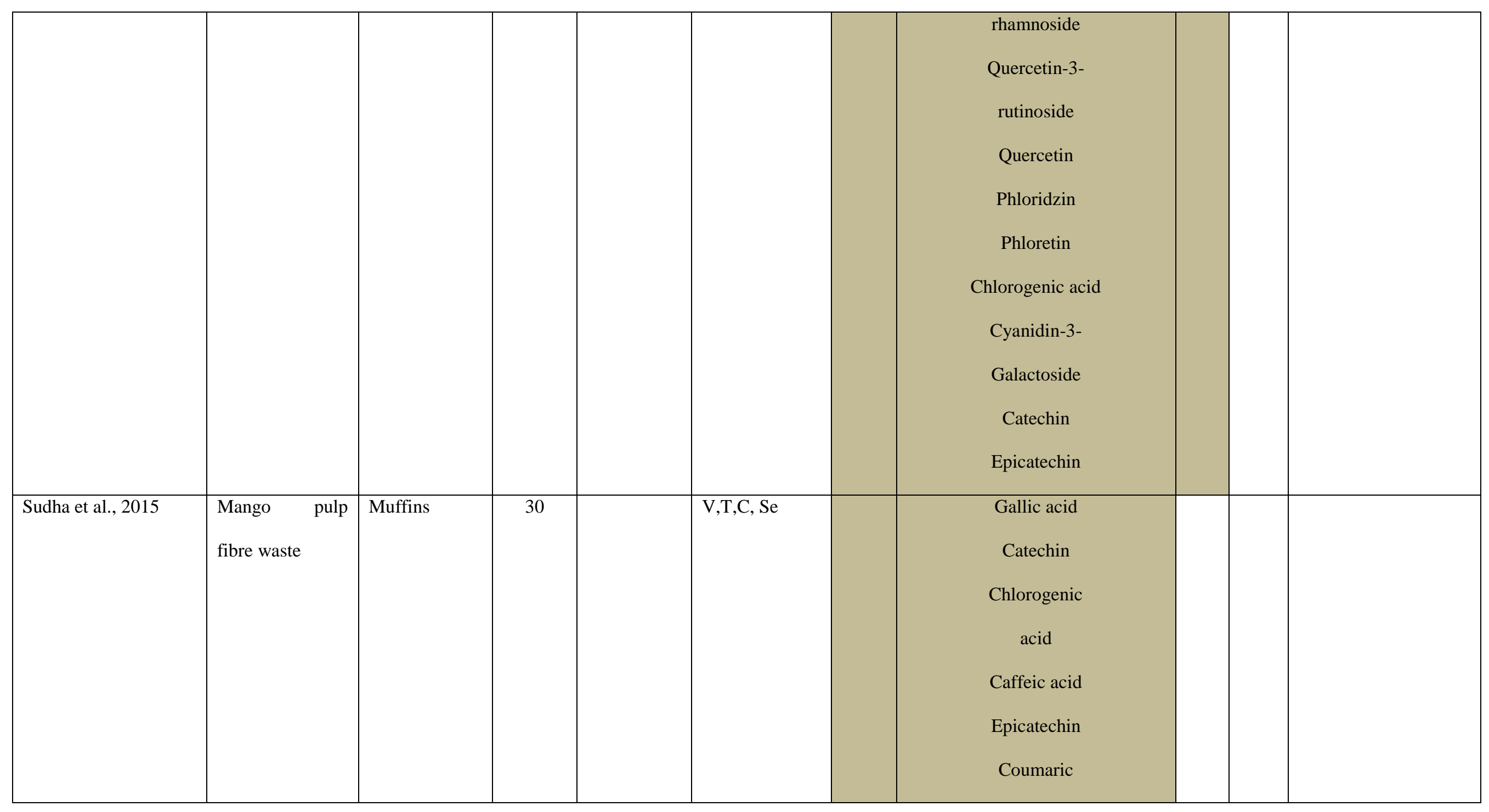




\begin{tabular}{|c|c|c|c|c|c|c|}
\hline & & & & & & $\begin{array}{c}\text { acid } \\
\text { Ferulic acid } \\
\text { Trans cinnamic } \\
\text { acid }\end{array}$ \\
\hline Sudha et al., 2016 & Apple pomace & Muffins & 40 & & $\mathrm{~V}, \mathrm{~T}, \mathrm{Se}$ & \\
\hline $\begin{array}{l}\text { Agama-Acevedo, } \\
2012\end{array}$ & $\begin{array}{l}\text { Unripe banana } \\
\text { flour }\end{array}$ & Cookies & 50 & & & \\
\hline Ajila et al., 2008 & Mango peel & Cookies & 20 & $\mathrm{~F}$ & $\mathrm{D}, \mathrm{T}, \mathrm{C}, \mathrm{Se}$ & Carotenoids \\
\hline $\begin{array}{l}\text { Arora and Camire, } \\
1994\end{array}$ & Potato peel & Cookies & 15 & & $\mathrm{D}, \mathrm{T}, \mathrm{C}, \mathrm{St}, \mathrm{Se}$ & \\
\hline Arun et al., 2015 & Banana peel & Cookies & 15 & & $\mathrm{D}, \mathrm{T}, \mathrm{C}, \mathrm{M}, \mathrm{Se}$ & \\
\hline Ferreira et al., 2015 & $\begin{array}{l}\text { Fruit and } \\
\text { vegetable } \\
\text { bagasse }\end{array}$ & Cookies & 35 & & $\mathrm{Se}$ & \\
\hline Kohajdova et al., 2011 & $\begin{array}{l}\text { Citrus dietary } \\
\text { fiber }\end{array}$ & Cookies & 15 & $\mathrm{~F}$ & $\mathrm{D}, \mathrm{C}, \mathrm{Se}$ & \\
\hline Kohajdova et al., 2013 & Grapefruits fiber & Cookies & 15 & $\mathrm{~F}$ & $\mathrm{D}, \mathrm{Se}$ & \\
\hline Kohajdova et al., 2014 & Apple pomace & Cookies & 15 & $\mathrm{~F}$ & $\mathrm{D}, \mathrm{Se}$ & \\
\hline
\end{tabular}




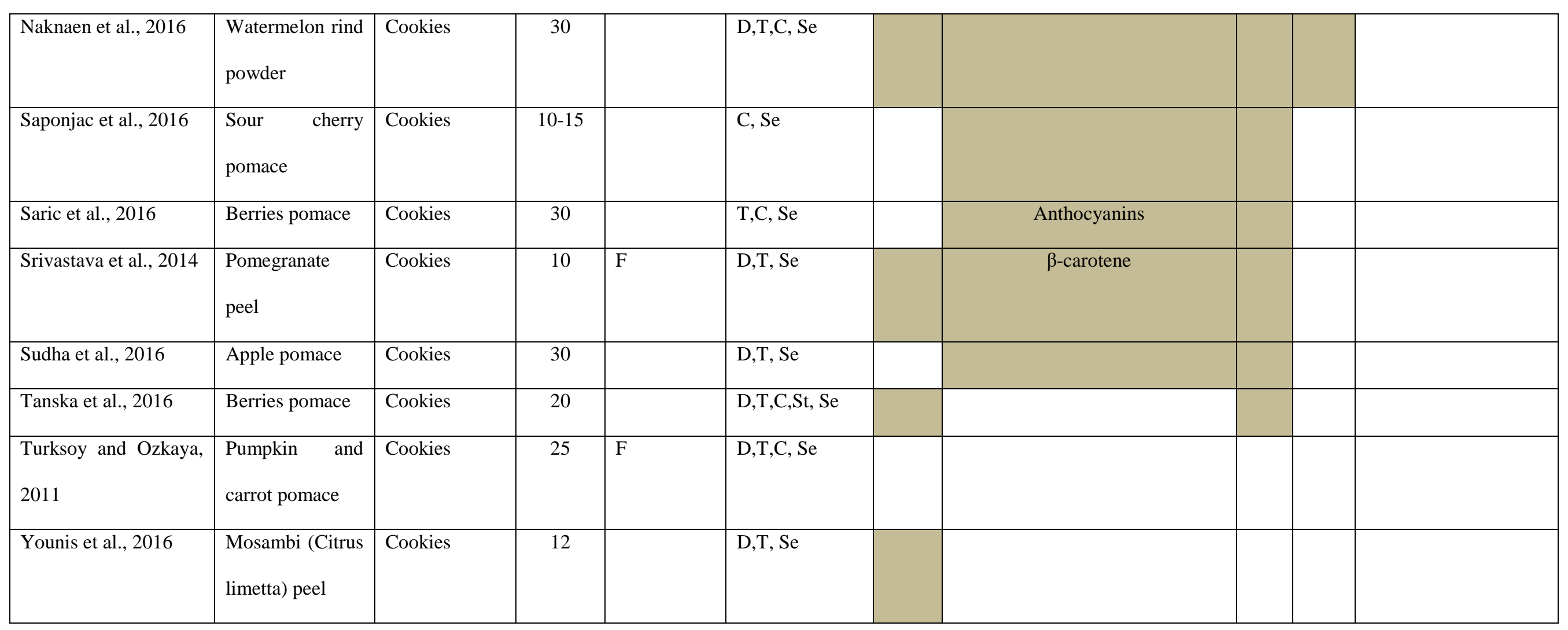

${ }^{\text {a }}$ Shaded cells indicate that the corresponding test described for each column was performed

${ }^{\mathrm{b}}$ Maximum percent of flour replacement by the fruit and vegetable by-product

${ }^{c}$ Physical characteristics of the dough as evaluated by farinograph or mixolab (F), batter density ( $\left.\rho\right)$, texture (T) and batter apparent viscosity (V) 
${ }^{\mathrm{d}}$ Physical quality of breads as evaluated by their volume (V), dimensions (D), height $(\mathrm{H})$, texture (T), color $(\mathrm{C})$, staling (St), microstructure (M) or sensory analysis $(\mathrm{Se})$

${ }^{\mathrm{e}}$ In most studies, polyphenols were analyzed following the Folin-Ciocalteau method for the total phenolic content. Studies containing other additional characterization for bioactive compounds are also described in the table.

${ }^{\mathrm{f}}$ Antioxidant capacity

${ }^{\mathrm{g}}$ Glycemic index determined in vitro 